\title{
A Physical Initialization Method for the Economical Prognostic
}

\author{
Arakawa-Schubert Scheme
}

\author{
By Kazumasa Aonashi \\ Meteorological Research Institute, Tsukuba-shi, Ibaraki-ken, Japan. \\ Ken-ichi Kuma and Yasuhiro Matsushita \\ Numerical Prediction Division, Japan Meteorological Agency, Chiyoda-ku, Tokyo-to, Japan.
}

(Manuscript received 6 August 1996, in revised form 13 February 1997)

\begin{abstract}
A physical initialization method for the economical prognostic Arakawa-Schubert scheme (EPAS) is developed to incorporate observed precipitation data into a numerical weather prediction model. The method adopted is a variational approach which minimizes the difference between the first guess and the initialized model variables, subject to strong constraints on precipitation areas and precipitation rates. The physical initialization method is divided into 2 parts:

(1) Adjustment of the initial thermodynamic variables such that the model precipitation areas diagnosed from the adjusted variables become consistent with the observed precipitation areas at the initial time.

(2) Adjustment of the initial cloud-base mass flux $(\mathrm{Mb})$ in such a way that the model precipitation rates are equal to the observed precipitation rates.

In order to examine the impact of the physical initialization method, forecast experiments for a case study of Typhoon WALT (T9407) were performed.

The results of the forecast experiments indicate that the physical initialization method eliminated the spin-up error of precipitation forecast for the first one hour, and reduced the positional error of precipitation forecasts for the first few hours.

The results suggest that the adjustment of the initial cloud base mass flux was essential for eliminating the spin-up error. It is also found that the adjustment of the initial cloud base mass flux contributed to reduce the positional error by strengthening the model convective precipitation around the observed heavy-rain area, and that the adjustment of the initial thermodynamic variables reduced the positional error by removing extreme moist-convective instability in the observed rain-free areas.
\end{abstract}

\section{Introduction}

Recent development in remote-sensing technology (such as airborne radars, satellite microwave radiometers) has provided us with precipitation retrievals over wide regions. Launches of earth observing satellites (TRMM, ADEOS-II etc.) in the near future will enable us to obtain the global precipitation data sets.

It is well known that precipitation process has close interaction with the large-scale thermodynamic and dynamic tendencies, and that quality of the precipitation observation has become better than that of the divergence fields. Hence, precipita-

(C)1997, Meteorological Society of Japan tion data have attracted the attention of many studies as the input data sets to numerical weather prediction (NWP) models. Most NWP models, however, can not use precipitation data directly because precipitation itself is not a prognostic variable but is obtained from other model variables by utilizing precipitation parameterization schemes.

Krishnamurti et al. (1984) proposed "the physical initialization" method to incorporate precipitation data into an NWP model indirectly. This method makes use of precipitation parameterization schemes to adjust the model's initial variables in order to retrieve the observed precipitation. The results of Krishnamurti et al. (1984) and other studies (Donner 1988; Aonashi 1993) revealed the importance of the 
physical initialization as a means of incorporation of observed precipitation data.

One difficulty with physical initialization is that different techniques are required for different precipitation parameterization schemes. So far, physical initialization methods for Kuo-type schemes (Krishnamurti et al. 1984; Donner 1988) and a moist convective adjustment scheme (Aonashi 1993) have been established. The development of the physical initialization method for Arakawa-Schubert-type schemes, however, are at the early stage, while some studies (for example, Kasahara et al. 1996) have worked on this problem.

The purpose of this study is to develop a physical initialization method for the economical prognostic Arakawa-Schubert scheme (Kuma 1993) which is a simplified Arakawa-Schubert-type scheme. (Hereafter this scheme is referred as to EPAS.)

In this study, the physical initialization method adopts a variational approach. The method is to minimize a cost function which consists of the difference between the objective analysis and the model variables subject to physical constraints on precipitation areas and precipitation rates. The physical initialization is divided into 2 parts:

(1) Adjustment of the initial thermodynamic variables such that the model precipitation areas diagnosed from the adjusted variables become consistent with the observed precipitation areas at the initial time.

(2) Adjustment of the initial cloud-base mass flux $(\mathrm{Mb})$ in such a way that the model precipitation rates are equal to the observed precipitation rates.

In order to examine the impacts of the physical initialization method, forecast experiments from the initial time of 00 UTC 23 July 1994 on a case study of Typhoon WALT (T9407) were performed.

\section{Description of the NWP model and data}

\subsection{Description of the model}

The present study uses the Japan Spectral Model (JSM), which is developed by the Japan Meteorological Agency (JMA) (see Segami et al. 1989 for details). The model is a 23-level spectral limited area model with a horizontal resolution of about $30 \mathrm{~km}$. The precipitation parameterization schemes of JSM originally used are a large-scale condensation scheme (LSC) and a moist convective adjustment scheme (MCA) proposed by Gadd and Keers (1970). In this study, we employ the economical prognostic Arakawa-Schubert scheme (EPAS) instead of MCA to parameterize the convective precipitation process in moist-convectively unstable areas.

\subsection{Description of EPAS}

EPAS is a simplified Arakawa-Schubert-type (AS) scheme developed by the staff members of the Numerical Prediction Division (NPD), JMA. The physical basis of AS schemes is the "quasi-equilibrium hypothesis" which assumes balance between the rate of generation of moist convective instability by largescale forcing and compensation by cumulus convection. Accordingly, convective precipitation is triggered by the AS scheme when the model atmosphere becomes moist-convectively unstable. Arakawa and Schubert (1974) expressed moist convective instability for a given cloud-top level as a cloud work function (CWF) $A(Z t)$ :

$$
A(Z t)=\int_{Z d}^{Z t} \frac{(T c-\bar{T}}{\bar{T}} \eta(Z t, z) g d z,
$$

where $Z t$ and $Z d$ are the cloud top and cloud base levels, and $T c$ and $\bar{T}$ are the cloud and the environmental temperatures, $\eta(Z t, z)$ is the normalized mass flux for the cloud top $Z t$, respectively. As Eq. (1) shows, $A(Z t)$ is a function of thermodynamic variables. Using CWF, the quasi-equilibrium hypothesis is written as:

$$
\frac{\partial A(Z t)}{\partial t}=\left\{\frac{\partial A(Z t)}{\partial t}\right\}_{L S}+\left\{\frac{\partial A(Z t)}{\partial t}\right\}_{c} \approx 0
$$

where $\left\{\frac{\partial A(Z t)}{\partial t}\right\}_{L S}$ and $\left\{\frac{\partial A(Z t)}{\partial t}\right\}_{c}$ are the rate of change of CWF by the large-scale forcing and the cumulus compensation of CWF which is a function of the cloud base mass flux $\mathrm{Mb}$, respectively.

The original AS scheme calculated $\mathrm{Mb}$ for all cloud-top levels simultaneously to maintain quasiequilibrium. In practice, however, this calculation is very time-consuming and computationally unstable for some cases. For alleviating this problem, Randall and Pan (1993) proposed a "prognostic AS scheme" which relaxed the quasi-equilibrium hypothesis. Their basic idea is to predict $\mathrm{Mb}$ :

$$
\frac{\partial M b(Z t)}{\partial t}=\frac{1}{2 \alpha}(A(Z t)-A o(Z t))
$$

where $M b(Z t)$ is the cloud base mass flux whose top level is $Z t, A o(Z t)$ is the empirically-determined threshold of $A(Z t)$, and $\left(10^{7} \mathrm{~m}^{4} \mathrm{~kg}^{-1}\right)$ is the prescribed parameter of the convective adjustment time, respectively. Since a negative cloud base mass flux is physically unacceptable, $M b(Z t)$ is set to be zero if the predicted value of $M b(Z t)$ is negative. EPAS is also based on this relaxed quasi-equilibrium hypothesis.

In the NWP model using EPAS, $M b(Z t)$ is calculated by Eq. (3), when $(A(Z t)-A o(Z t))$ becomes positive due to the large-scale forcing. Then the convective precipitation rate and the cumulus effects 
on grid scale temperature and humidity are calculated as long as the predicted $M b(Z t)$ is positive. When the cumulus compensation becomes dominant, $(A(Z t)-A o(Z t))$ falls below zero. This depresses the convection by reducing $M b(Z t)$ to zero. Through these processes, EPAS relaxes the moistconvectively unstable atmosphere towards the equilibrium state:

$$
A(Z t) \approx A o(Z t)
$$

\subsection{Objective analysis}

The operational objective analysis of JMA (Kashiwagi 1990) provides the objective analysis of winds, temperature, geopotential and relative humidity on a $40 \mathrm{~km}$ resolution grid at 14 pressure levels and sea surface pressure for 00 and 12 UTC. As a first guess for the objective analysis, a 12-hour forecast of JSM starting with data 12 hours prior to the initial time is used in this study.

When a typhoon exists, the operational objective analysis also uses "typhoon bogus" data in order to obtain better information on the position of the typhoon center and the vortex structure. Bogus observations of geopotential height, sea surface pressure and winds around the typhoon are generated from manually-analyzed typhoon indices using empirical techniques (Ueno 1989).

For the operational JSM forecasts, this analysis is interpolated to the JSM grid to make the initial condition. In this study, we use these interpolated data as the first guess for the physical initialization.

\subsection{Precipitation data}

The observed precipitation rates are obtained from the operational hourly precipitation analysis of JMA. A detailed explanation of this system is given by Takase et al. (1988). After the hourly precipitation data (horizontal resolution of $5 \mathrm{~km}$ ) are interpolated to the JSM grids (horizontal resolution of about $30 \mathrm{~km}$ ), the interpolated data are used as the observed precipitation rates in this study.

Observed precipitation areas are defined by grid points which have an observed precipitation rate of more than the threshold value of $0.5 \mathrm{~mm} \mathrm{~h}^{-1}$.

\section{The physical initialization method}

\subsection{The basic theory}

This subsection will describe the basic idea of the physical initialization method for EPAS. The physical initialization method for LSC is described by Aonashi (1993). The purpose of the physical initialization is to find the optimally-adjusted initial variables subject to strong constraints on precipitation. In a variational form, this problem can be written as follows :

$$
\begin{aligned}
& \operatorname{minimize} J=\left(X^{a}-X^{g}\right)^{t} B^{-1}\left(X^{a}-X^{g}\right) \\
& \text { subject to Rain }{ }^{c}=\text { Rain }^{o}
\end{aligned}
$$

where $X^{a}$ and $X^{g}$ are the first guess and the optimally-adjusted initial variables, $B$ is forecast error covariance matrix, superscript $t$ denotes the transpose of vectors, Rain ${ }^{\circ}$ is the observed precipitation, Rain $^{c}$ is precipitation calculated by the precipitation parameterization schemes, respectively. It is convenient to introduce the Lagrangian associated with the above constrained minimization problem, defined as $L=J+\lambda\left(\right.$ Raino $^{o}-$ Rainc $\left.^{c}\right)$, where $\lambda$ is a Lagrangian multiplier.

From this point, $B$ is assumed to be diagonal for simplicity. When using this assumption, the problem of the physical initialization is to determine the optimal adjustment for every horizontal grid point :

$$
\begin{aligned}
L(i)= & \left(X^{a}(i)-X^{g}(i)\right)^{t} B^{-1}(i)\left(X^{a}(i)-X^{g}(i)\right) \\
& +\lambda\left(\text { Rain }(i)^{o}-\operatorname{Rain}(i)^{c}\right), \\
& (\text { for } i=1, \text { Imax }),
\end{aligned}
$$

where $X^{a}(i)$ and $X^{g}(i)$ are the first guess and the optimally-adjusted initial variables at a horizontal grid point $(i)$, respectively. $B(i)$ is a forecast error variance at horizontal grid point $(i)$. Imax is the number of the horizontal grid points.

As discussed in Section 2.2, EPAS is based on the following assumptions :

(1) The "quasi-equilibrium state" of the model thermodynamic variables (temperature and humidity) exists in the model precipitation areas.

(2) The model precipitation rate is a function of the cloud-base mass flux.

From these assumptions, it is concluded that the constraints on precipitation areas and precipitation rates in the physical initialization for EPAS are imposed only on the initial thermodynamic variables and the initial cloud-base mass flux, respectively. Accordingly, Eq. (6) is divided into 2 Lagrangians :

$$
\begin{aligned}
L_{T}(i) & =\sum_{k}\left\{\frac{\left(T_{k}^{a}(i)-T_{k}^{g}(i)\right)^{2}}{2 \sigma_{T}{ }^{2}}+\frac{\left(q_{k}^{a}(i)-q_{k}^{g}(i)\right)^{2}}{2 \sigma_{q}{ }^{2}}\right\} \frac{d P}{g} \\
& +\lambda 1\left(F L G^{o}-F L G^{c}\right), \\
& (\text { for } i=1, \operatorname{Imax}), \\
L_{M}(i) & =\sum_{k}\left\{\frac{\left(M b_{k}^{a}(i)-M b_{k}^{g}(i)\right)^{2}}{2 \sigma_{M}^{2}}\right\} \frac{d P}{g} \\
& +\lambda 2\left(P r^{o}-P r^{c}\right), \\
& (\text { for } i=1, \operatorname{Imax}),
\end{aligned}
$$

where $T$ and $q$ are temperature and specific humidity at a k-th level at horizontal grid point (i), FLG and $\mathrm{Pr}^{\circ}$ are the observed rain flag (the index indicating the existence of precipitation) and the precipitation rate, $F L G^{c}$ and $P r^{c}$ are the rain flag and the precipitation rate calculated by the precipitation parameterization schemes, $\lambda 1$ and $\lambda 2$ are Lagrangian multipliers, $M b$ is the cloud-base mass flux for a 
cloud-top level $k, d P$ is the difference in pressure between $k$-th and $(k+1)$-th level, respectively.

Using the quasi-equilibrium state of the thermodynamic variables, the constraint on precipitation areas is expressed in terms of the CWFs as follows:

(1) The initial CWF in observed precipitation areas satisfies the critical state, $A o(Z t)-A(Z t)=0$, for at least one cloud-top level such that EPAS generates model precipitation.

(2) The super critical state of the CWF, $A o(Z t)-$ $A(Z t)<0$, does not exist in the initial fields, including observed precipitation areas and rain free areas.

Thus, for a given cloud-top level $Z t$, Eq. (7) can be rewritten :

$$
\begin{aligned}
L_{t}(i)= & \sum_{k}\left\{\frac{\left(T_{k}^{a}(i)-T_{k}^{g}(i)\right)^{2}}{2 \sigma_{t}{ }^{2}}+\frac{\left(q_{k}^{a}(i)-q_{k}^{g}(i)\right)^{2}}{2 \sigma_{q}{ }^{2}}\right\} \frac{d P}{g} \\
& +\lambda 1(A o(Z t(i))-A(Z t(i))),
\end{aligned}
$$

This study utilizes this cost function to the physical initialization of the thermodynamic variables. The Euler-Lagrange equation for Eq. (9) is :

$$
\begin{gathered}
\frac{\left(T_{k}^{a}(i)-T_{k}^{g}(i)\right)}{\sigma_{q}^{2}} \frac{d P}{g}-\lambda 1 \frac{\partial A(Z t(i))}{\partial T_{k}}=0, \\
\frac{\left(q_{k}^{a}(i)-q_{k}^{g}(i)\right)}{\sigma_{q}-2} \frac{d P}{g}-\lambda 1 \frac{\partial A(Z t(i))}{\partial q_{k}}=0 \\
\sum_{k}\left\{\frac{\partial A(Z t(i))}{\partial T_{k}}\left(T_{k}^{a}(i)-T_{k}^{g}(i)\right)\right. \\
\left.+\frac{\partial A(Z t(i))}{\partial q_{k}}\left(q_{k}^{a}(i)-q_{k}^{g}(i)\right)\right\} \\
=(A o(Z t(i))-A(Z t(i))),
\end{gathered}
$$

where $\frac{\partial A(Z t(i))}{\partial T_{k}}$ and $\frac{\partial A(Z t(i))}{\partial q_{k}}$ are the rates of change of $A(Z t)$ by the change of $T$ and $q$, respectively. The optimal adjustment of the initial thermodynamic variables is given by solving Eqs. (10)-(12) for an appropriate cloud-top level in observed precipitation areas and for all cloud-top levels with the super critical state.

Equation (8) is directly applied to the physical initialization of the cloud-base mass flux. The EulerLagrange equation for Eq. (8) is :

$$
\begin{aligned}
& \frac{M b_{k}^{a}(i)-M b_{k}^{g}(i)}{\sigma_{M}^{2}} \frac{d P}{g}-\lambda 2 \frac{\partial P r^{c}}{\partial M b_{k}}=0 \\
& \sum_{k} \frac{\partial P r^{c}}{\partial M b_{k}}\left(M b_{k}^{a}(i)-M b_{k}^{g}(i)\right)=\left(P r^{o}-P r^{c}\right),
\end{aligned}
$$

where $\frac{\partial P r^{c}}{\partial M b_{k}}$ is the rate of change of $\operatorname{Pr}$ by the change of $M b$. Solving Eqs. (13) and (14) gives the optimal adjustment of the initial cloud-base mass flux for EPAS.

\subsection{The initialization procedures}

Figure 1 shows the schematic of the initialization procedures of this study. The first procedure of the initialization method of this study is to calculate the precipitation rate and the moist convective instability at the initial time from the first guess. This is because different initialization methods are required for incorporation of precipitation data in accordance with moist convective instability, since the critical state for LSC (relative humidity $(\mathrm{RH})=$ $100 \%)$ is above the critical state for EPAS in moistconvectively unstable regions. The physical initialization method of Aonashi(1993) is applied to adjust the initial RH such that the model precipitation areas are consistent with the observation in moistconvectively stable regions. Similarly, the physical initialization method for EPAS adjusts the initial thermodynamic variables in moist-convectively unstable regions. Adjustment of the initial cloud-base mass flux is also executed in moist-convectively unstable regions from the difference in precipitation rate between the observation and the first guess. After the above adjustment, Non-linear normal mode initialization (NNMI) incorporating the precipitation processes (Aonashi 1993) is executed to attain the initial divergence balanced with the adjusted model precipitation. The NNMI also adjusts the precipitation rate due to LSC in order to approximate the model precipitation rate to the observational data.

The remainder of this subsection will describe the above procedures in detail.

\subsubsection{Calculation of the precipitation rate and moist convective instability from the first-guess field}

The first guess of the model precipitation rate is calculated from the advective tendencies of the firstguess temperature and humidity, following Aonashi (1993). An atmospheric column at a horizontal grid point is assumed to be moist-convectively stable if the CWF calculated from the first guess of temperature and humidity is below zero for all cloud-top levels. If this is not satisfied, the grid point is considered to be moist-convectively unstable.

\subsubsection{Adjustment of the thermodynamic variables in moist-convectively stable regions}

A physical initialization method developed by Aonashi(1993) is applied to the RH modification within moist-convectively stable regions. This method raises $\mathrm{RH}$ to $\mathrm{RHc}(=100 \%)$ between the lifted condensation level of the surface air $(\mathrm{Pb})$ and cloudtop level (Pct) in observed precipitation areas if the model does not predict precipitation. Pct corresponds to the cloud-top black-body temperature $(\mathrm{Tbb})$ measured by the Japanese geostationary satellite GMS4 at the initial time.

In the observed rain-free areas, $\mathrm{RH}$ is set to $\mathrm{RHd}$ $(=\mathrm{RHc}-5 \%)$ if $\mathrm{RH}$ is larger than $\mathrm{RHd}$. This is to 


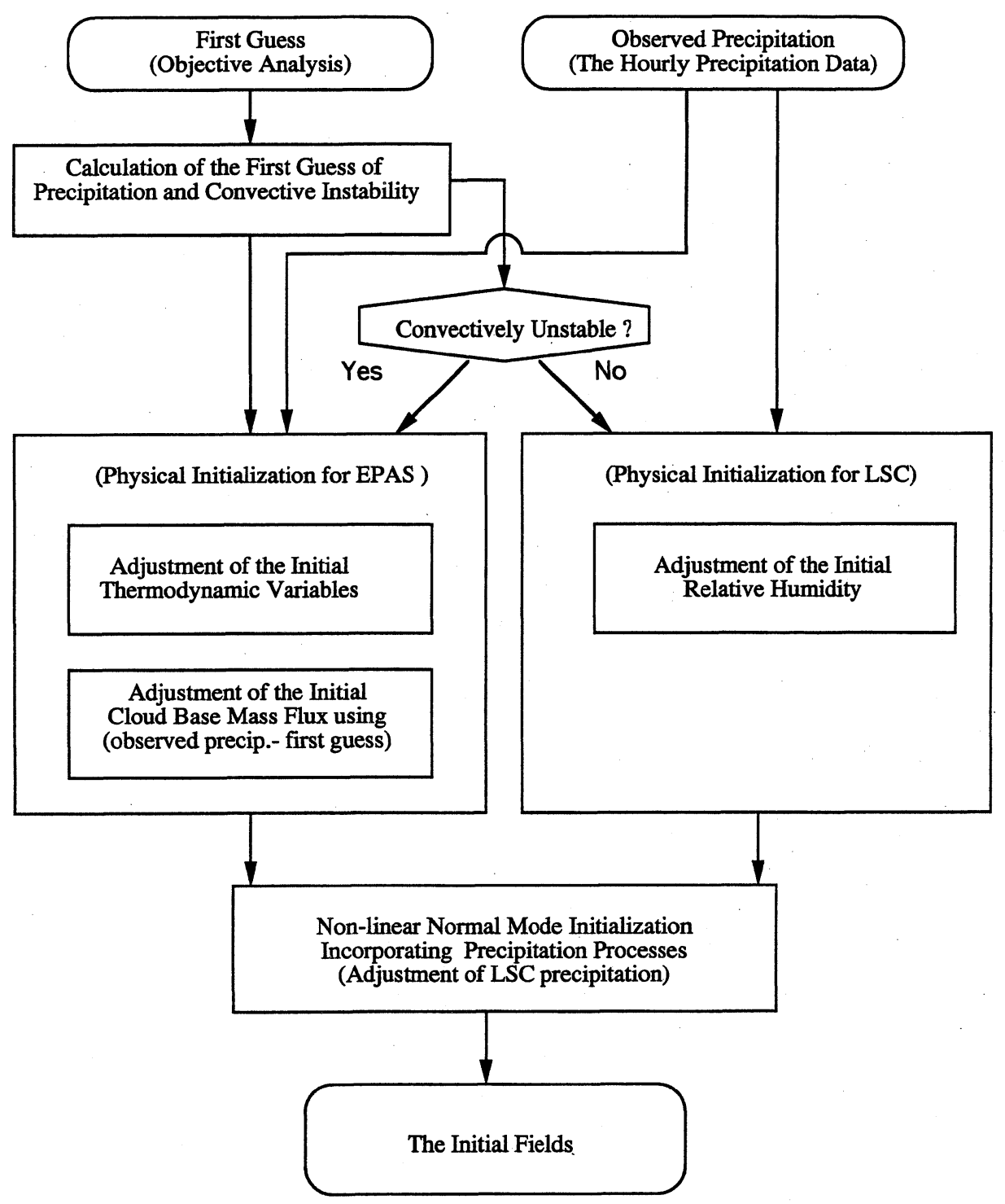

Fig. 1. The schematic of the initialization procedure of this study.

suppress LSC precipitation in the areas where the observations indicate no rain.

\subsubsection{Adjustment of the thermodynamic variables in} moist-convectively unstable regions

Based on the discussion in Section 3.1, this procedure modifies the first guess of temperature and humidity such that the critical state, $A o(Z t)-A(Z t)=$ 0 , is satisfied for at least one cloud-top level in observed precipitation areas, and that the super critical state, $A o(Z t)-A(Z t)<0$, does not exist in the whole domain.

First, the coefficients $\frac{\partial A(Z t)}{\partial T_{k}}$ and $\frac{\partial A(Z t(i))}{\partial q_{k}}$ in Eqs. (10)-(12) are obtained as follows:

The first guess of the CWF is computed from the first guess of temperature and humidity $\left(T^{g}, q^{g}\right)$. Then we calculate and using the following approxi- mation:

$$
\begin{aligned}
& \frac{\partial A(Z t(i))}{\partial T_{k}} \\
& =\frac{A\left(Z t\left(T^{g}(i)+\Delta T_{k}, q^{g}(i)\right)-A\left(Z t\left(T^{g}(i), q^{g}(i)\right)\right.\right.}{\Delta T_{k}}, \\
& \frac{\partial A(Z t(i))}{\partial q_{k}} \\
& =\frac{A\left(Z t\left(T^{g}(i), q^{g}(i)+\Delta q_{k}\right)-A\left(Z t\left(T^{g}(i), q^{g}(i)\right)\right.\right.}{\Delta q_{k}},
\end{aligned}
$$

where $\Delta T_{k}$ and $\Delta q_{k}$ are an increment of temperature and specific humidity at a $k$-th level, respectively. 
We prescribe and in Eqs. (10) and (11) as follows:

$$
\begin{aligned}
\sigma_{T}= & 2.0(K) \quad(900 \mathrm{hPa}>P>300 \mathrm{hPa}) \\
& 4.0 *(P / P s-0.6) * * 2(K) \\
& (P>900 \mathrm{hPa} \text { or } P<300 \mathrm{hPa}), \quad(17) \\
\sigma_{q}= & q s(T) *(0.1-0.12 *(P-P s) / P s)(\mathrm{g} / \mathrm{kg}),
\end{aligned}
$$

where $P$ and $P s$ are the pressure at the k-th level and the surface level, $q s$ is the saturated specific humidity, respectively. These values are determined based on statistical researches on forecast error of JMA NWP models (NPD 1989 ; Aonashi and Shibata 1996).

Next, we check whether the super critical state $(A o(Z t)-A(Z t)<0)$ exists in the first guess. Then, the adjustment of temperature and specific humidity by solving Eqs. (10)-(12) is executed in order to reduce $A(Z t)$ to $A o(Z t)$ for all cloud-top levels with the super critical state.

Next, the thermodynamic variables in the observed precipitation areas are adjusted to achieve the critical state for an appropriate cloud-top level. In this study, it is assumed that the cloud-top level is located between Pct and (Pct+200 hPa). If CWFs within this range are below the critical state, this procedure chooses the most unstable cloud-top level (i.e. the minimum $A o(Z t)-A(Z t))$ in this range. Then, the adjustment of temperature and specific humidity by solving Eqs. (10)-(12) is executed for this level.

\subsubsection{Adjustment of the initial cloud-base mass flux} in moist-convectively unstable regions

This procedure adjusts the initial cloud-base mass flux in order to approximate the model precipitation rate to the observation at the initial time. For this purpose, it is necessary to obtain $M b_{k}^{g}$ and $\frac{\partial P r^{c}}{\partial M b_{k}}$ from the initial fields after the adjustment of thermodynamic variables.

First, this procedure calculates whose cumulus compensation is balanced with $\left\{\frac{\partial A(Z t)}{\partial t}\right\}_{L S}$, the initial large scale forcing in the following iterative manner:

(1) At first, $M b_{k}(t 0)$, the cloud-base mass flux at the initial time is set to be zero.

(2) CWFs at the first step of time integration, $(A(Z t(t 0+\Delta t))$ are calculated from the temperature and humidity after a time interval, .

(3) $M b_{k}(t 0+\Delta t)$ is obtained from $A(Z t(t 0+\Delta t))$ and $M b_{k}(t 0)$ using Eq. (3). Then $M b_{k}(t 0+\Delta t)$ is substituted into $M b_{k}(t 0)$

(4) $M b_{k}(t 0)$ is used to calculate temperature and humidity modification by EPAS and the convective precipitation rate for a cloud-top level $k, P r_{k}^{c}$, over a time interval .
(5) The above procedures ((2)-(4)) are iterated until $A(Z t(t 0+\Delta t))$ becomes equal to $A(Z t(t 0))$ (i.e. the cumulus compensation calculated from $M b_{k}(t 0)$ is balanced with the large-scale forcing).

This study assumes that $M b_{k}^{g}$ is equal to $M b_{k}(t 0)$ computed by the above iteration.

Next, $\frac{\partial P r^{c}}{\partial M b_{k}}$ is obtained from $M b_{k}^{g}$ and $P r_{k}^{c}$ using the following approximation :

$$
\frac{\partial P r^{c}}{\partial M b_{k}} \approx \frac{P r_{k}^{c}}{M b_{k}^{g}} \text {. }
$$

Adjustment of the cloud-base mass flux is calculated by solving Eqs. (13) and (14), using $M b_{k}^{g}$, $\frac{\partial P r^{c}}{\partial M b_{k}}$ and difference between the observed precipitation rate and the first guess of the model precipitation rate. In this calculation, $\sigma_{M}$ is prescribed to be constant in the vertical for simplicity.

In the observed rain-free areas, $M b_{k}^{a}$ is set to zero for all cloud-top levels in order to suppress convective precipitation at the initial time.

\subsubsection{Non-linear normal mode initialization incor-} porating the precipitation processes

A NNMI method incorporating the precipitation processes (Aonashi 1993) is utilized. This method employs Machenhaeur's scheme (1977) to suppress gravity wave noise and adjusts the amplitude of high-frequency gravity modes. The NNMI adjusts the gravity waves of the first five vertical modes with a short cut-off period of 6 hours.

The NNMI of this study utilizes EPAS and LSC schemes to include the diabatic heating term due to precipitation into the rate of change of temperature.

Using the diabatic initialization method developed by Turpeinen et al. (1990), the NNMI adjusts the precipitation rate due to LSC such that the model precipitation rate (i.e. the sum of large scale and convective precipitation rate) approximates to the observed precipitation rate at the initial time.

\section{Forecast experiments and results}

\subsection{The meteorological case}

The physical initialization method was applied to the case study of Typhoon Walt (T9407) at 00 UTC 23 July 1994.

Figure 2 shows the objective analysis of the sea surface pressure and winds for this time. At this time, the center of the typhoon was at $\left(29.7^{\circ} \mathrm{N}\right.$, $\left.132.9^{\circ} \mathrm{E}\right)$ over the sea southeast of Kyushu Island (western part of Japan), and the minimum central pressure was $975 \mathrm{hPa}$.

Figure 3 shows the GMS4 Tbb image for 00 UTC 23 July 1994. The low-Tbb area near the typhoon center was confined to several tens of kilometers from the center. A cumulonimbus band along $131^{\circ} \mathrm{E}$ was also evident to the west of the center. 


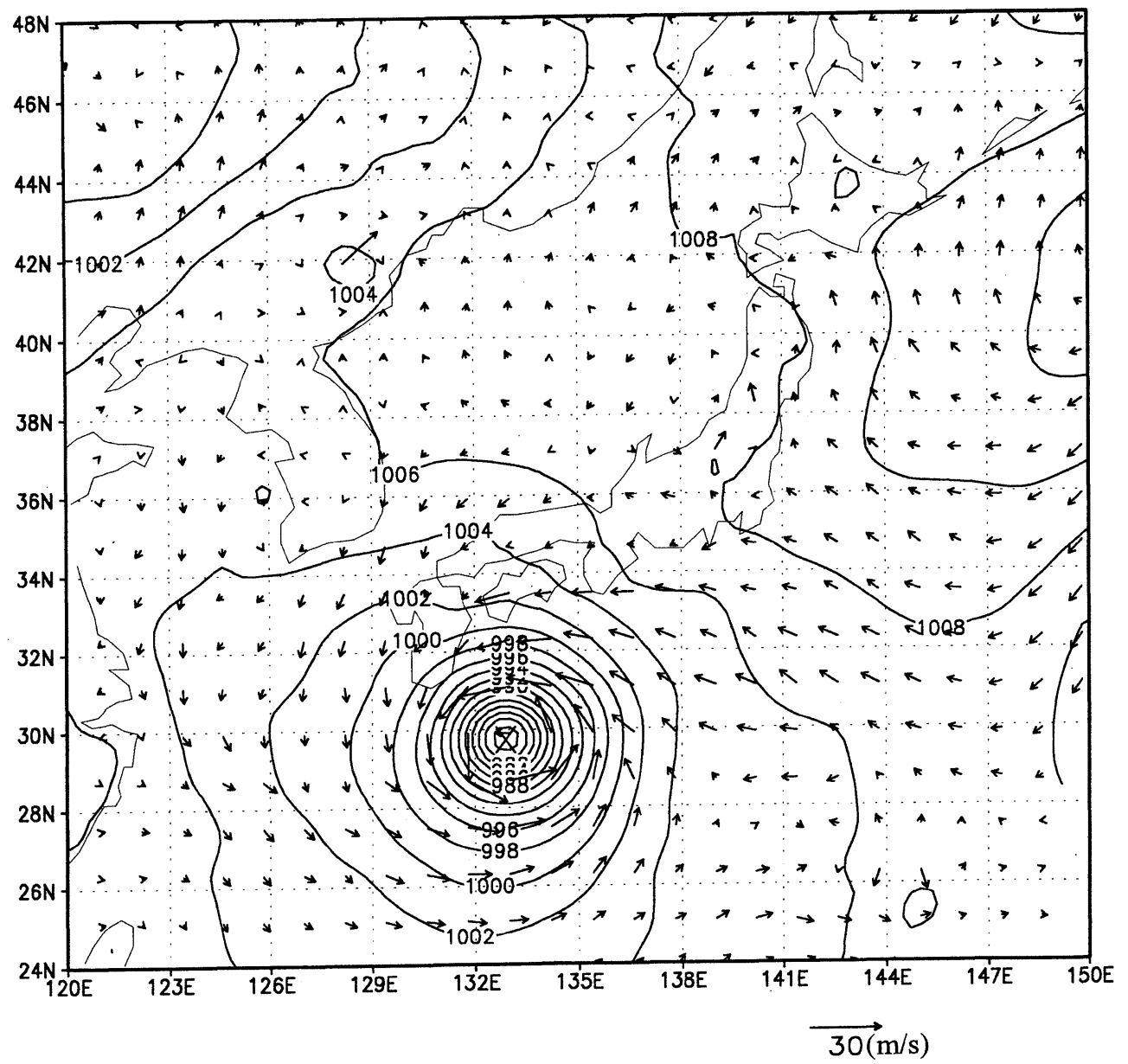

Fig. 2. The objective analysis of the sea surface pressure and winds for 00 UTC 23 July 1994. Contours and vectors are the surface pressure (at every $2 \mathrm{hPa}$ ) and the surface wind speed, respectively. $X$ represents the center of typhoon Walt.

Figure 4 shows the observed hourly precipitation data around the southwestern part of Japan for 23 UTC 22-04 UTC 23 July 1994, which is given by the JMA precipitation analysis. During this period, the southeastern quarter of the typhoon was out of the detection range of the JMA precipitation analysis. As Fig. 4 indicates, there existed rain areas mainly in the western sector of the Typhoon (along $131^{\circ} \mathrm{E}$ ) and on the coast of Ki-i Peninsula $\left(33^{\circ}-34^{\circ} \mathrm{N}, 135^{\circ}-137^{\circ} \mathrm{E}\right)$ for this period. In the northern sector of the typhoon, rain areas were found for 00-02 UTC. Heavy rain was observed around $\left(30^{\circ} \mathrm{N}, 130.5^{\circ} \mathrm{E}\right)-\left(28.5^{\circ} \mathrm{N}, 131.5^{\circ} \mathrm{E}\right)$ for $00-02$ UTC (hereafter referred to as Area A) and around $\left(31.0^{\circ} \mathrm{N}, 131^{\circ} \mathrm{E}\right)-\left(29.5^{\circ} \mathrm{N}, 131^{\circ} \mathrm{E}\right)$ for $01-$ 04 UTC (hereafter referred to as Area B) in the western sector.

\subsection{The experimental procedure}

In this study, we performed forecast experiments from the initial time of 00 UTC 23 July 1994 using the observed hourly precipitation for 23 UTC 22-
00 UTC 23 July 1994.

To evaluate the impact of the physical initialization of this study, a JSM forecast using the technique described in Section 3 (hereafter referred to as PI) was compared with a JSM forecast without the physical initialization (hereafter referred to as $\mathrm{RT}$ ) . In experiment RT, the first guess of the thermodynamic variables was used as the initial condition, and the initial cloud-base mass flux was set to be zero. RT employed only the NNMI incorporating the precipitation processes as the initialization procedure.

The individual roles of the physical initialization of the thermodynamic variables and the initialization of the cloud-base mass flux were examined with the following experiments:

(1) Experiment TH : A JSM forecast which employed the physical initialization method of this study except for the adjustment of initial cloudbase mass flux. 


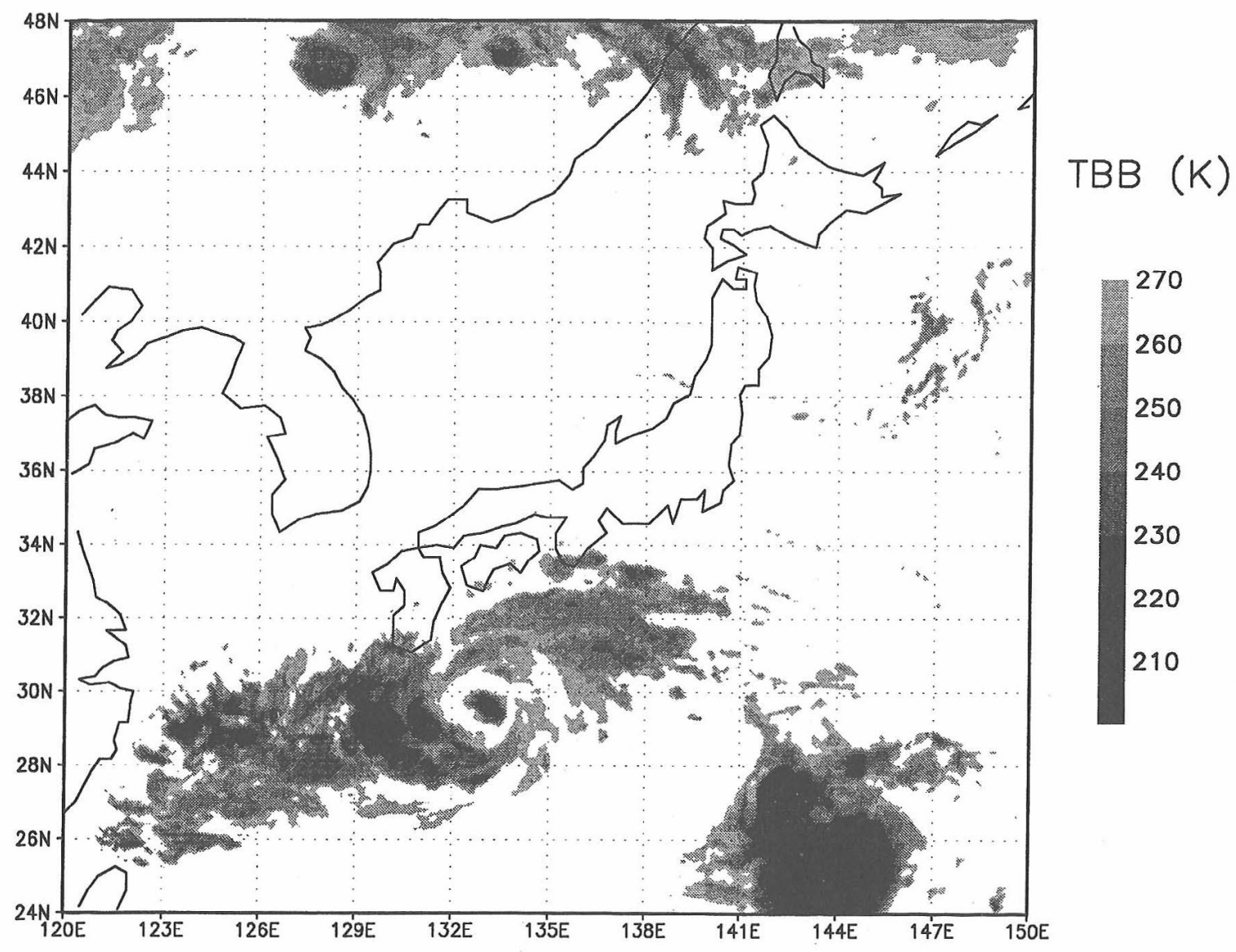

Fig. 3. GMS4 black-body temperature $(K)$ for 00 UTC 23 July 1994.

(2) Experiment IM : A JSM forecast which employed the physical initialization method of this study except for the adjustment of the initial thermodynamic variables.

\subsection{Initial fields and from $R T$}

\subsubsection{The initial fields}

Figure 5 shows the vertically- averaged moist convective instability $(A(Z t(t 0+\Delta t))-A o(Z t))$ computed from the initial thermodynamic variables for RT (i.e. the first guess). This figure indicates that there existed an extensive moist-convectively unstable region to the west of the typhoon, and that the very unstable areas were located in the vicinity of the typhoon center (around $\left(29.3^{\circ} \mathrm{N}, 131.9^{\circ} \mathrm{E}\right)$, hereafter referred to as Area $\mathrm{C}$ ) and to the southwest of Area A (around $\left(28.4^{\circ} \mathrm{N}, 130.8^{\circ} \mathrm{E}\right.$ ), hereafter referred to as Area D).

Figure 6 illustrates a vertical cross section (along $\left.29.3^{\circ} \mathrm{N}\right)$ of $(A(Z t(t 0+\Delta t))-A o(Z t))$ for RT. From this figure, it was found that the region around Area $\mathrm{C}$ was extremely unstable, not only for deep clouds (top level $\approx 140 \mathrm{hPa}$ ) but also for mid-level clouds (top level $\approx 450 \mathrm{hPa}$ ).

Figure 7 presents the initial RH at $850 \mathrm{hPa}$ for RT. The typhoon center $(X)$ was surrounded by a high-
$\mathrm{RH}$ region $(\mathrm{RH}>85 \%)$. This figure also reveals that there existed nearly saturated areas around $135.5^{\circ} \mathrm{E}$ (hereafter referred to as Area E) and $132^{\circ} \mathrm{E}$ (hereafter referred to as Area F), and that a local $\mathrm{RH}$ minimum was found to the east of the typhoon center $\left(30^{\circ} \mathrm{N}, 133^{\circ}-134^{\circ} \mathrm{E}\right)$. Area $\mathrm{A}$, the observed heavyrain area along $131^{\circ} \mathrm{E}$, corresponded with the western edge of the high- $\mathrm{RH}$ region around the typhoon at this level.

\subsubsection{Precipitation forecasts from $R T$}

Figure 8 shows convective and large-scale precipitation for 00-04 UTC 23 July 1994 from experiment RT. This figure indicates that precipitation forecast from RT had a spin-up error for zero to one hour. The model precipitation to the west of the typhoon center (hereafter referred to as Area G) for the first one hour is much weaker than the observed precipitation around Area A. The maximum of the convective precipitation was about $2-3 \mathrm{~mm} \mathrm{~h}^{-1}$, even in the very unstable regions Areas $\mathrm{C}$ and $\mathrm{D}$. Accordingly, the main reason for the slow spin-up over this region is considered to be the zero cloud-base mass flux at the initial time. It is also noteworthy that no precipitation was forecast from RT to the east of the typhoon center for 00-01 UTC, and that a 
(a) $\operatorname{RAM}(\mathrm{mm} / \mathrm{hr})$ for $23 z 22-00 z 23 \mathrm{Jul}$.

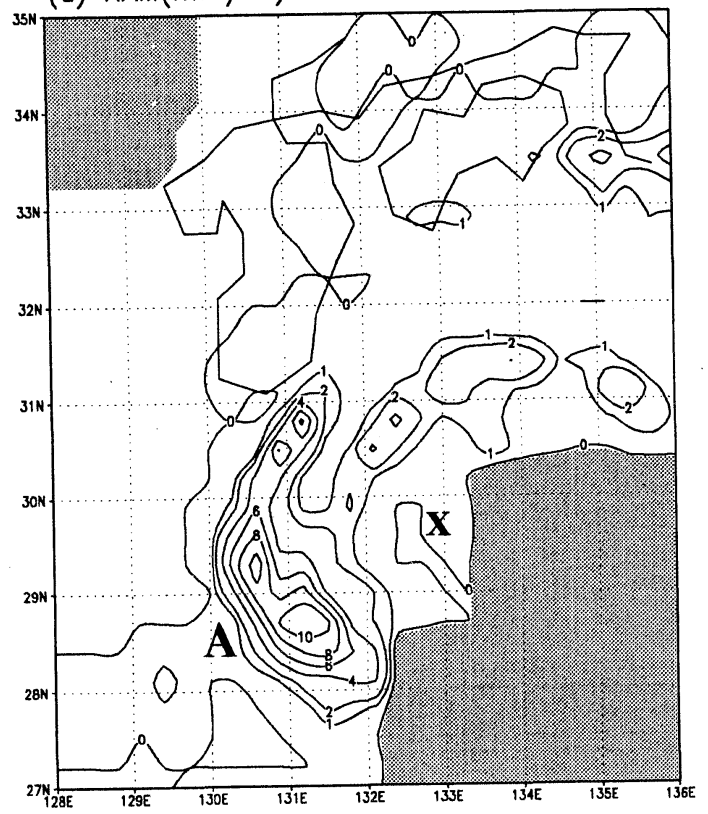

GrNS: COMIGES

(c) RAM (mm/hr) for 01-02z 23 Jul.

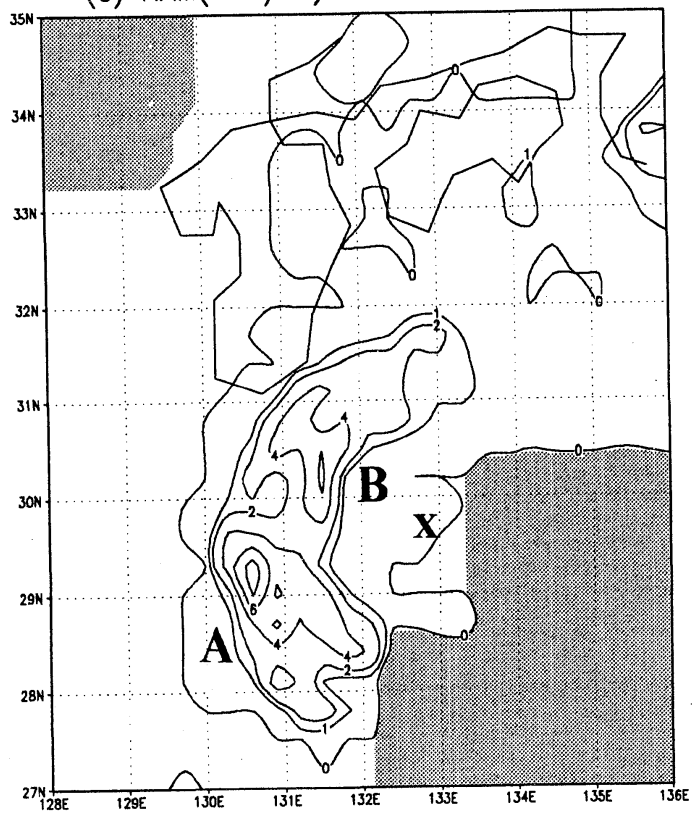

(b) RAM (mm $/ \mathrm{hr})$ for $00 \mathrm{z}-01 \mathrm{z} 23 \mathrm{Jul}$.

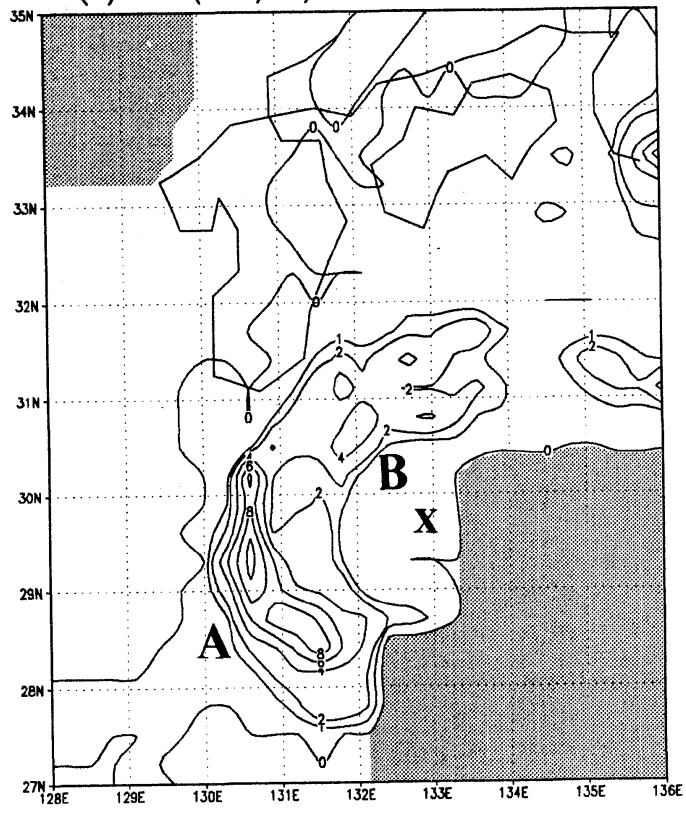

GNDS: CONMESS

(d) RAM $(\mathrm{mm} / \mathrm{hr})$ for $02-03 z 23 \mathrm{Jul}$.

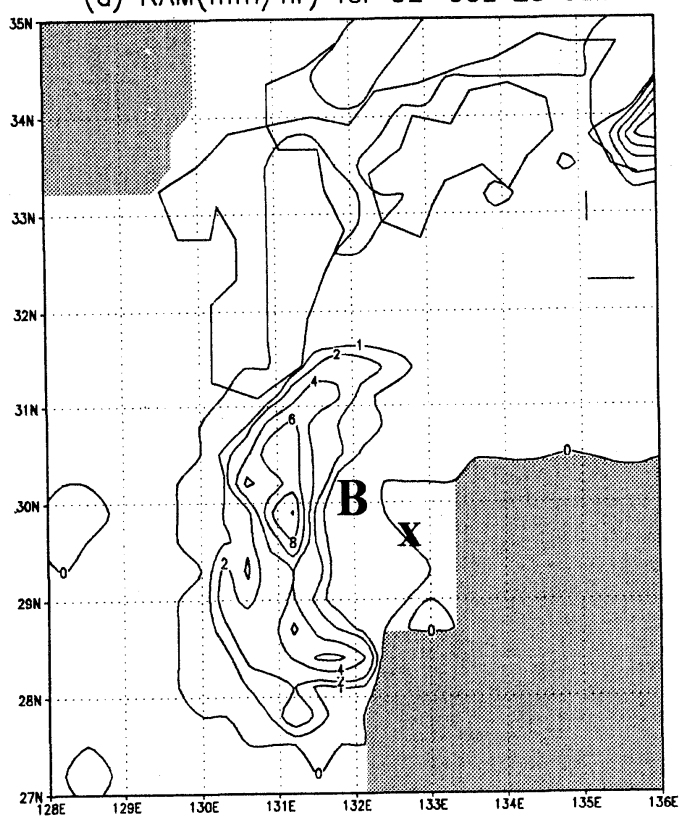

Fig. 4. The observed hourly precipitation, (a) for 23 UTC 22-00 UTC 23 July 1994, (b) for 00-01 UTC 23 July 1994 , (c) for 01-02 UTC 23 July 1994, (d) for 02-03 UTC 23 July 1994, (e) for 03-04 UTC 23 July 1994. Contours are at $0,1,2,4,6,8,10,12,16,20 \mathrm{~mm} \mathrm{~h}^{-1}$. Shaded areas are out of the observation ranges. $X$ represents the center of typhoon Walt. A and B represent heavy-rain areas around $\left(30^{\circ} \mathrm{N}, 130.5^{\circ} \mathrm{E}\right)-\left(28.5^{\circ} \mathrm{N}, 131.5^{\circ} \mathrm{E}\right)$ and around $\left(31^{\circ} \mathrm{N}, 131^{\circ} \mathrm{E}\right)-\left(29.5^{\circ} \mathrm{N}, 131^{\circ} \mathrm{E}\right)$, respectively. 
(e) RAM $(\mathrm{mm} / \mathrm{hr})$ for $03-04 \mathrm{z} 23 \mathrm{Jul}$.

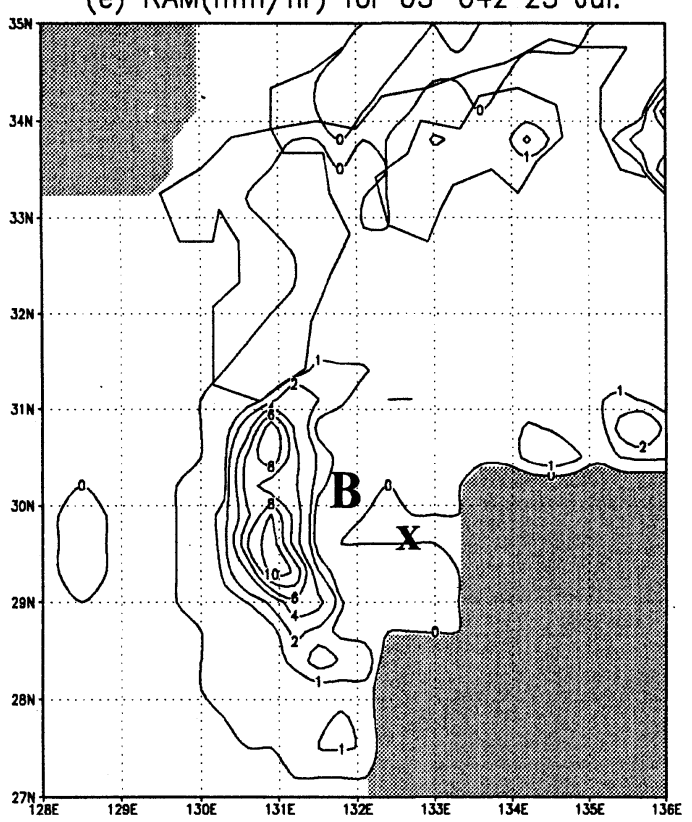

Fig. 4. (Continued)

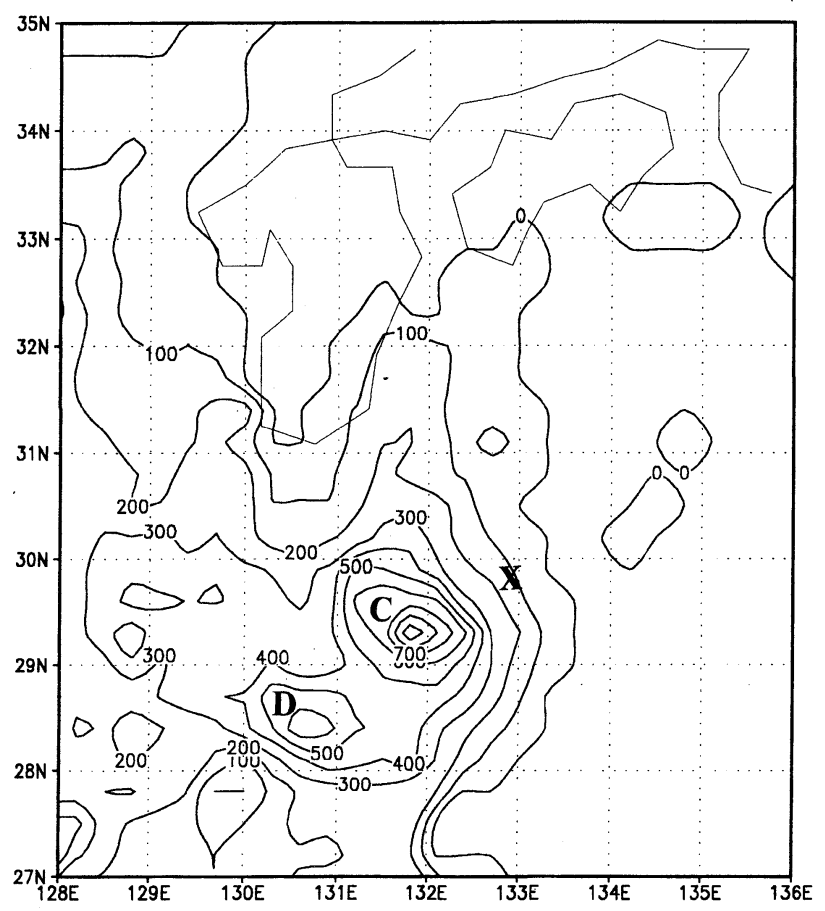

Fig. 5. A vertically-averaged moist convective instability $A(Z t(t 0+\Delta t))$ $A o(Z t)(\mathrm{J} / \mathrm{Kg})$ calculated from the initial thermodynamic variables for RT. $X$ is the centerer of typhoon Walt. $C$ and $D$ represent the very unstable areas around $\left(29.3^{\circ} \mathrm{N}, 131.9^{\circ} \mathrm{E}\right)$ and around $\left(28.4^{\circ} \mathrm{N}, 130.8^{\circ} \mathrm{E}\right)$, respectively. model precipitation area to the east of the typhoon center (hereafter referred to as Area $\mathrm{H}$ ) was generated after $01 \mathrm{UTC}$ in the vicinity of the local $\mathrm{RH}$ minimum in Fig. 7.

Comparison between this figure and Fig. 4 also indicates that RT had a positional error of precipitation forecasts: For 00-01 UTC, Area G, the model main precipitation area, was formed in the vicinity of Area F, whose location was about 100 $\mathrm{km}$ northeast of Area A. While the observed heavyrain band in the western sector was located between $130^{\circ}-132^{\circ} \mathrm{E}$ for $00-04 \mathrm{UTC}$, the model convective precipitation around Area $\mathrm{G}$ was confined in $131^{\circ}-$ $132^{\circ} \mathrm{E}$, within the very convectively unstable region.

$\mathrm{RT}$ also generated a convective rain band to the west-southwest of the rain band in the western sector during 00-04 UTC, though no precipitation was observed in that area (hereafter referred to as Area I). Comparing Fig. 8 with Fig. 5 suggests that this precipitation area was caused by release of the moist convective instability around Area D.

\subsection{Results of PI}

4.4.1 Adjustment of thermodynamic variables by the physical initialization

Figure 9 illustrates the vertical cross section of $\left(T_{k}^{a}-T_{k}^{g}\right)$ and $\left(q_{k}^{a}-q_{k}^{g}\right)$ given by the physical initialization of PI around the very unstable region along $29.3^{\circ} \mathrm{E}$. The physical initialization reduced the vertical lapse rate mainly by decreasing temperatures below the $950 \mathrm{hPa}$ level and increasing mid-level temperatures. In the region unstable to mid-level clouds $\left(130^{\circ}-132^{\circ} \mathrm{E}\right)$, the physical initialization also raised low-level temperatures $(700-800 \mathrm{hPa})$.

The adjustment of specific humidity by PI resulted in drying below the $950 \mathrm{hPa}$ level for most areas in Fig. 9b. Around $130^{\circ}-132^{\circ} \mathrm{E}$, however, humidity up to the $750 \mathrm{hPa}$ level was reduced. This is because the convective instability of the mid-level clouds has strong sensitivity, $\frac{\partial A(Z t)}{\partial q_{k}}$, to the humidity in this level due to the large entrainment rates.

The above adjustment made the initial condition nearly neutral for EPAS. Figure 10 shows the vertically-averaged moist convective instability , $A(Z t(t 0+\Delta t))-A o(Z t)$, computed from the initial thermodynamic variables for PI. The adjustment greatly reduced the moist convective instability in the vicinity of Areas C and D.

Figure 11 illustrates the vertical cross section (along $\left.29.3^{\circ} \mathrm{N}\right)$ of $A(Z t(t 0+\Delta t))-A o(Z t)$ for PI. Comparing this figure with Fig. 6 indicates that the extreme moist-convective instability in RT was removed by the adjustment of the thermodynamic variables.

\subsubsection{The initial cloud base mass flux}

Figure 12 illustrates a vertical cross section of the first guess of the initial cloud-base mass flux $\left(M b_{k}^{g}\right)$ 


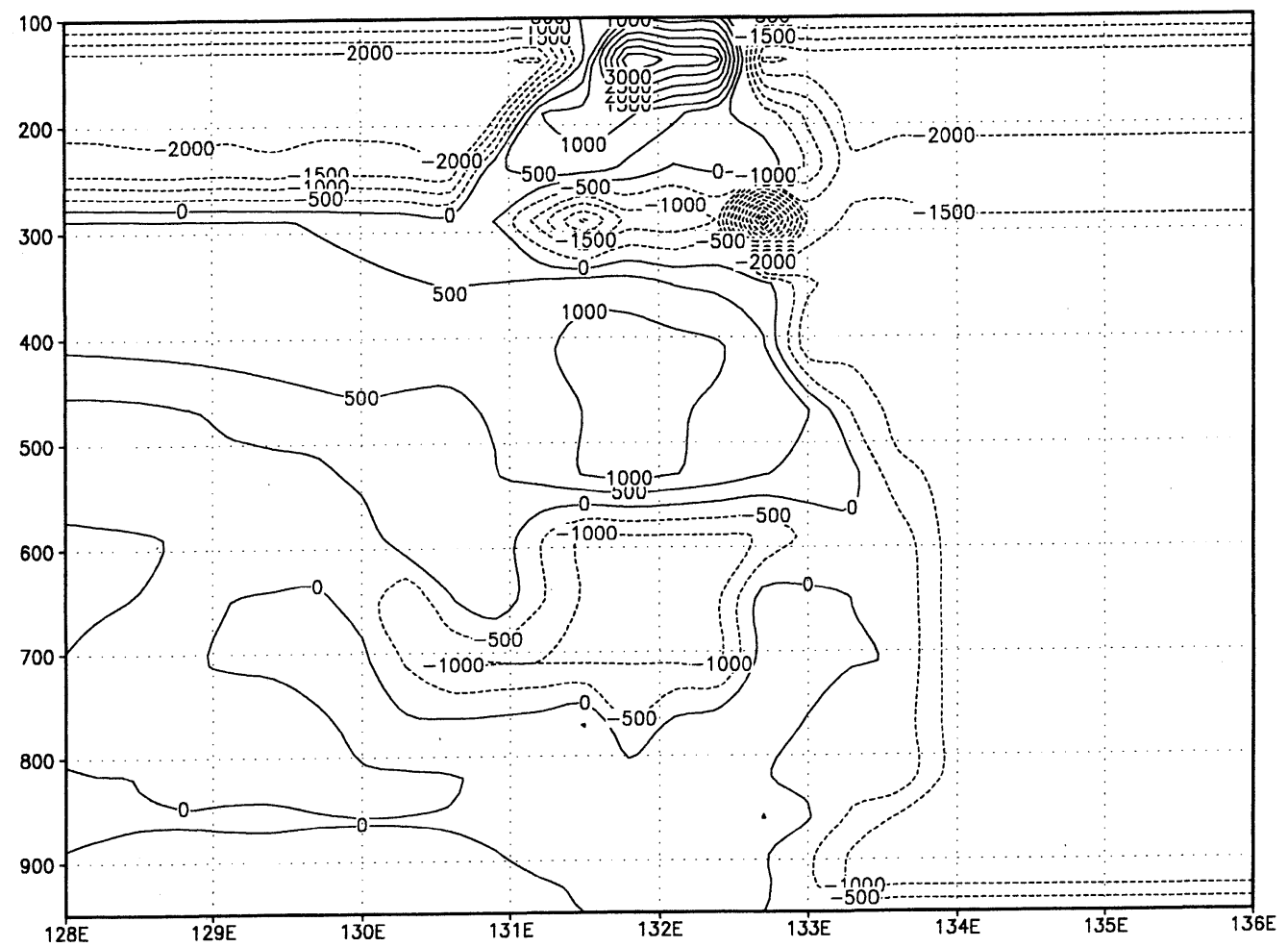

Fig. 6. A vertical cross section (along $\left.29.3^{\circ} \mathrm{N}\right)$ of $A(Z t(t 0+\Delta t))-A o(Z t)(\mathrm{J} / \mathrm{kg})$ for $\mathrm{RT}$.

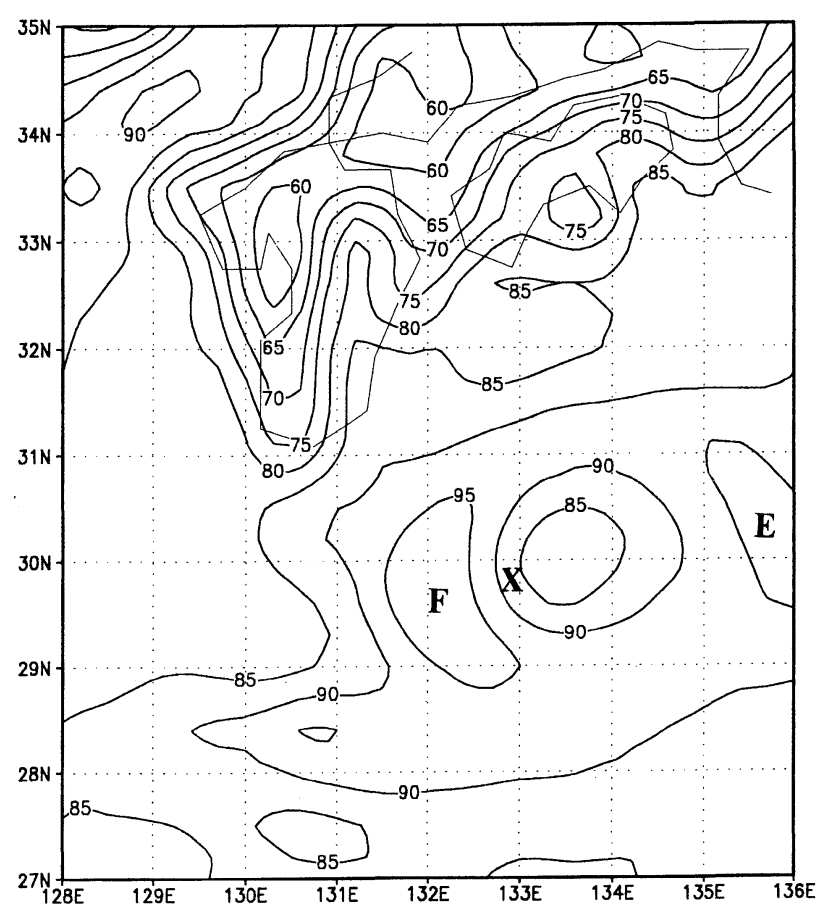

Fig. 7. Relative humidity at $1000 \mathrm{hPa}$ calculated from the first-guess variables. $X$ is the center of typhoon Walt. E and F represent nearly saturated areas around $135.5^{\circ} \mathrm{E}$ and around $132^{\circ} \mathrm{E}$. calculated from $\left\{\frac{\partial A(Z t)}{\partial t}\right\}_{L S}$ of PI. In the region of $131^{\circ}-133^{\circ} \mathrm{E}$, where RT had the maximum convective precipitation for the first one hour, large $M b_{k}^{g}$ was generated for cloud-top levels between 700$300 \mathrm{hPa}$. Outside this region, $M b_{k}^{g}$ had cloud-top levels around $400 \mathrm{hPa}$.

Figure 13 shows a vertical cross section of $\left(M b_{k}^{a}-\right.$ $M b_{k}^{g}$ ) obtained by solving Eqs. (13) and (14). The cloud-base mass flux was strengthened in the observed heavy-rain region $\left(130^{\circ} \mathrm{E}-131^{\circ} \mathrm{E}\right)$, while it was reduced in the maximum convective precipitation region of the first-guess field $\left(131^{\circ} \mathrm{E}-133^{\circ} \mathrm{E}\right)$.

The convective precipitation which is calculated from the initialized cloud-base mass flux appears in Fig. 14. The pattern of this convective precipitation was very close to that observed for 23 UTC 22-00 UTC 23 in convectively unstable areas in Fig. 5 .

\subsubsection{Precipitation forecasts from PI}

Figure 15 shows large-scale and convective precipitation for 00-04 UTC from experiment PI. The strength of forecast precipitation along $131^{\circ} \mathrm{E}$ (hereafter referred to as Area $\mathrm{J}$ ) is in good agreement with the observed precipitation for 00-01 UTC. This indicates that PI was successful in eliminating the spinup error for this region. The model precipitation areas for 00-01 UTC also included large-scale and convective precipitation areas in the northern sector of the typhoon (hereafter referred to as Area K). PI, 
(a) QPF (RT) for $00-01 z(\mathrm{~mm} / \mathrm{hr})$

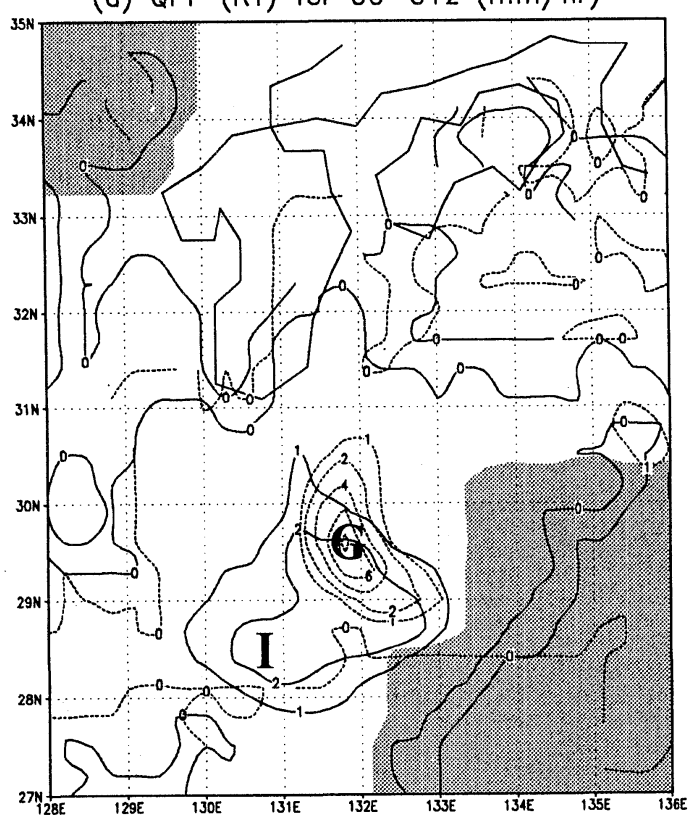

GNDS: COMGES

(c) QPF (RT) for $02-03 z(\mathrm{~mm} / \mathrm{hr})$

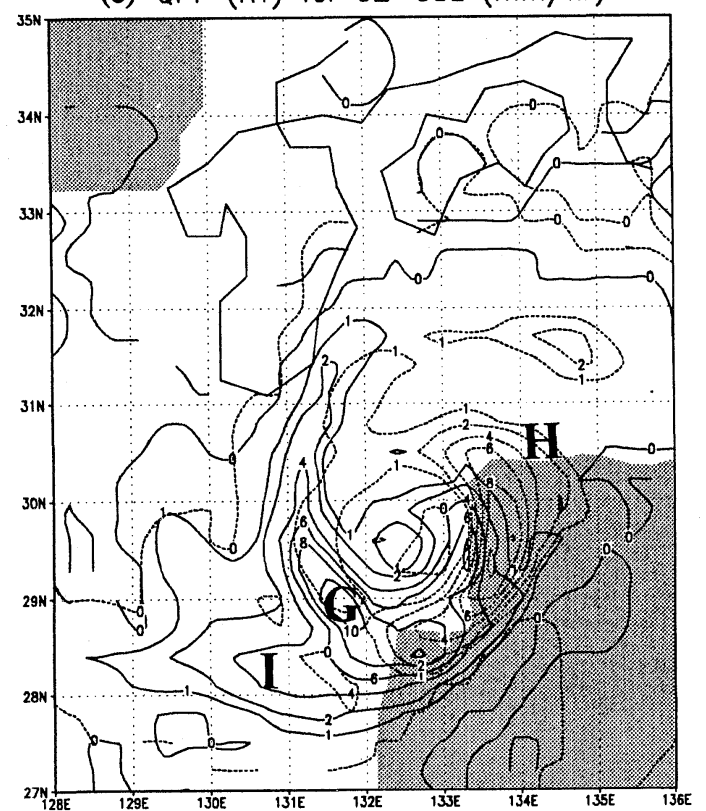

(b) QPF (RT) for $01-02 z(\mathrm{~mm} / \mathrm{hr})$

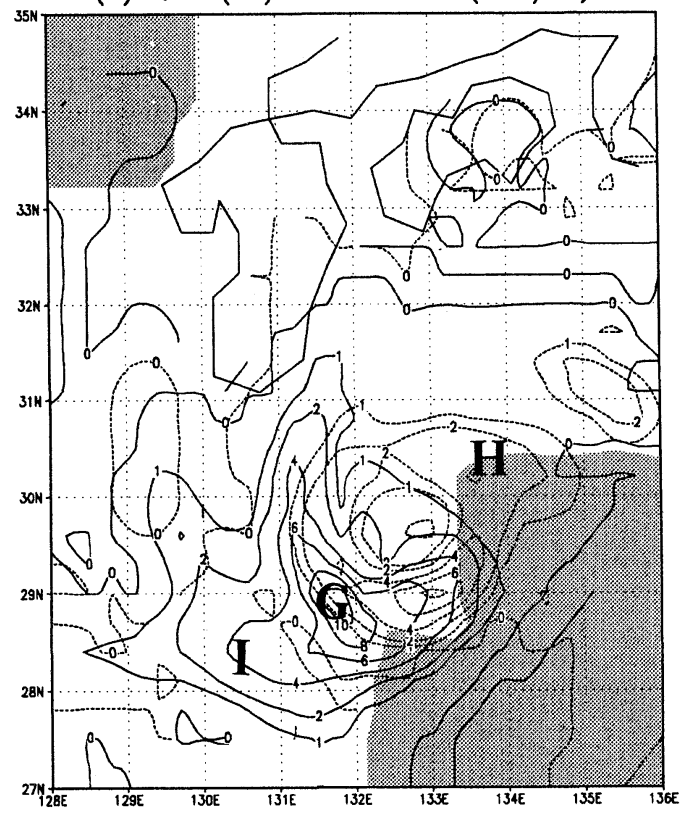

GrNS: COMMGES

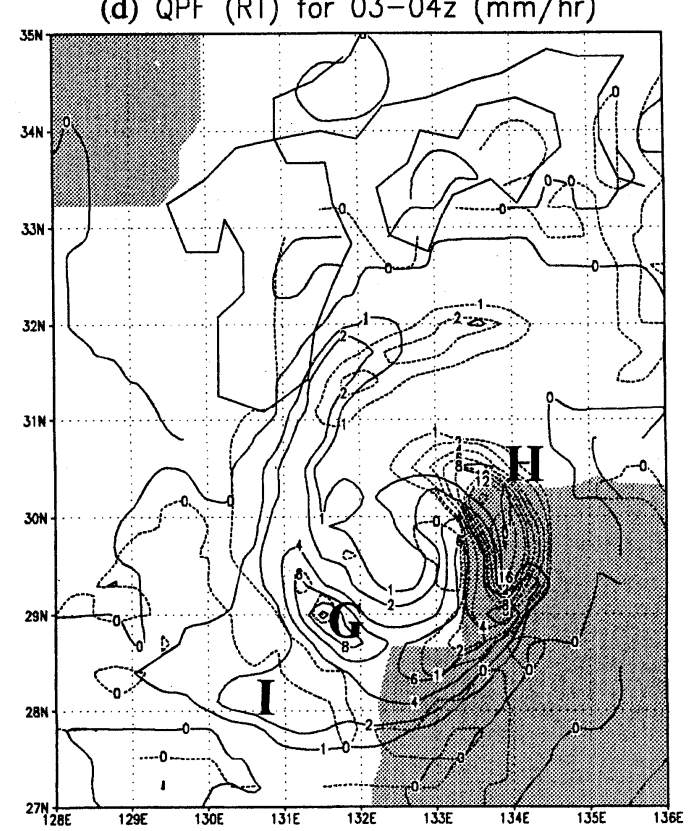

Fig. 8. Convective and large scale precipitation from RT. (a) for 00-01 UTC 23 July 1994 , (b) for 01-02 UTC 23 July 1994, (c) for 02-03 UTC 23 July 1994, (d) for 03-04 UTC 23 July 1994. Contours are at $0,1,2,4,6,8,10,12,16,20 \mathrm{~mm} \mathrm{~h}^{-1}$. Solid and dashed lines represent convective and large-scale precipitation, respectively. Shaded areas are out of the observation ranges of the hourly precipitation analysis. $\mathrm{G}$ and $\mathrm{H}$ represent the model precipitation areas to the west of the typhoon and to the east of the typhoon center, respectively. I represents a convective precipitation area in the western sector of the typhoon. 
(a)

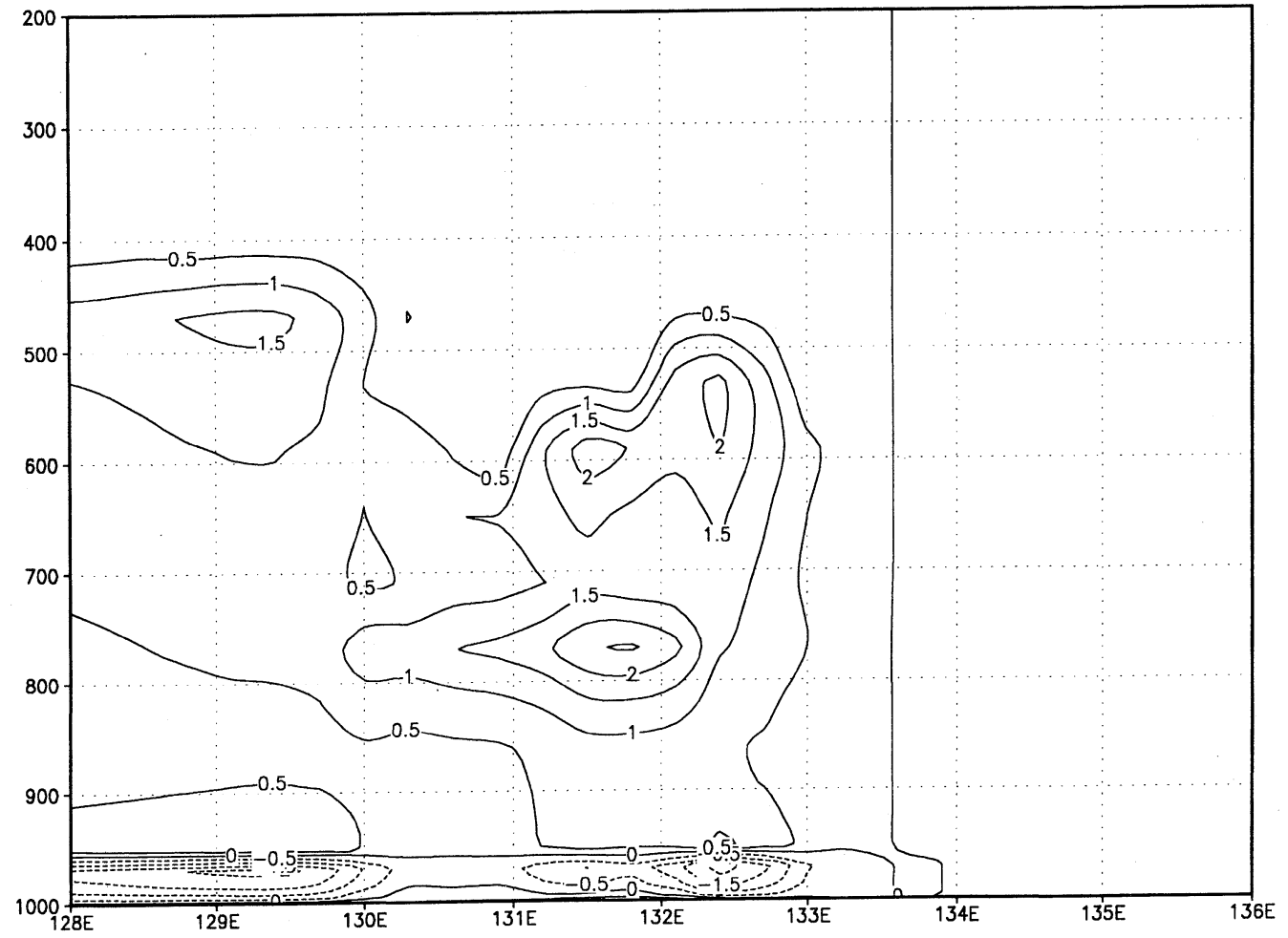

(b)

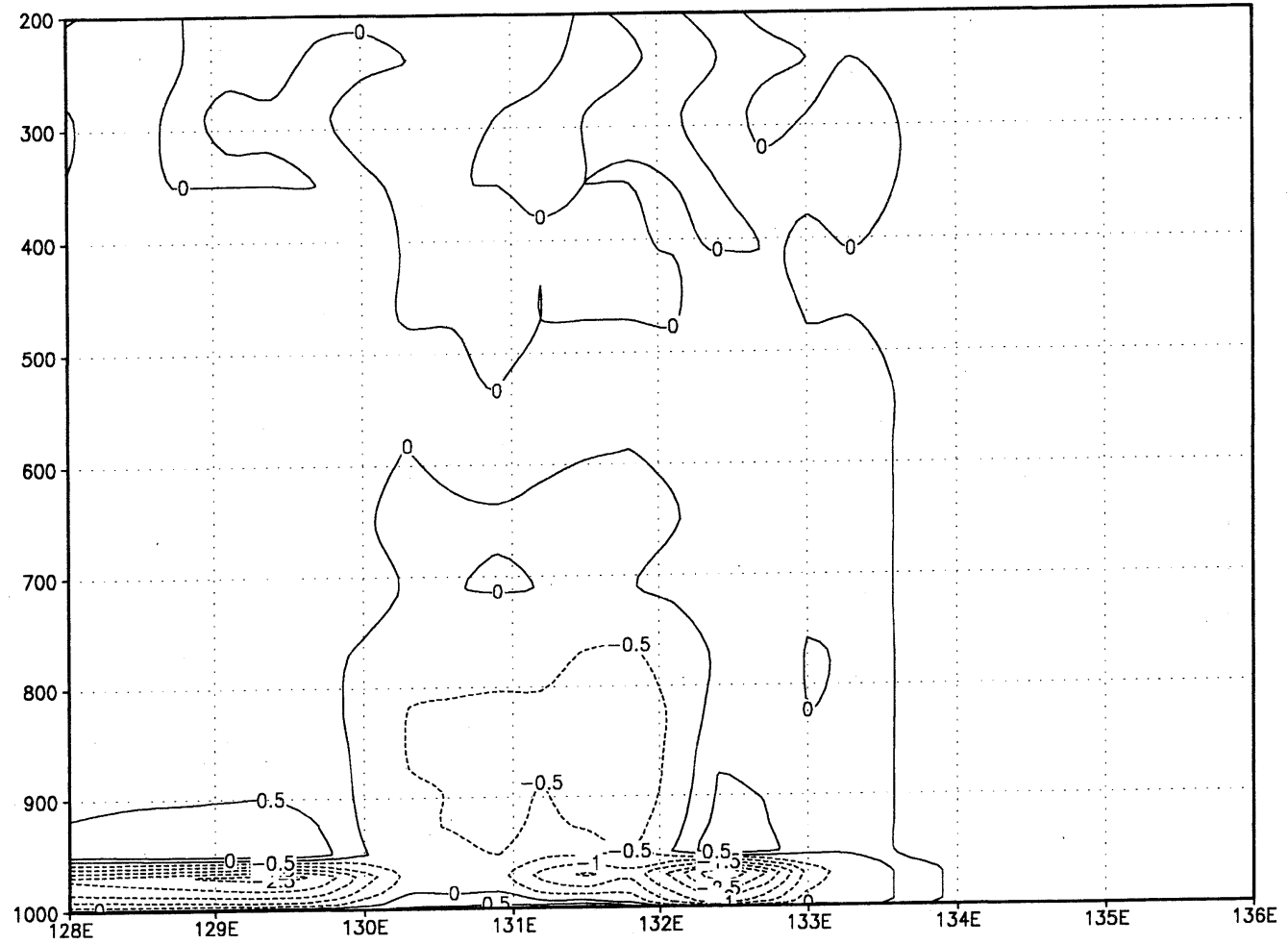

Fig. 9. (a) A vertical cross section (along $29.3^{\circ} \mathrm{N}$ ) of adjustment of initial temperature Contours are at every $0.5 \mathrm{~K}$. Dashed lines are negative. (b) A vertical cross section (along $29.3^{\circ} \mathrm{N}$ ) of adjustment of initial specific humidity. Contours are at every $0.5 \mathrm{~g} \mathrm{~kg}^{-1}$. Dashed lines are negative. 


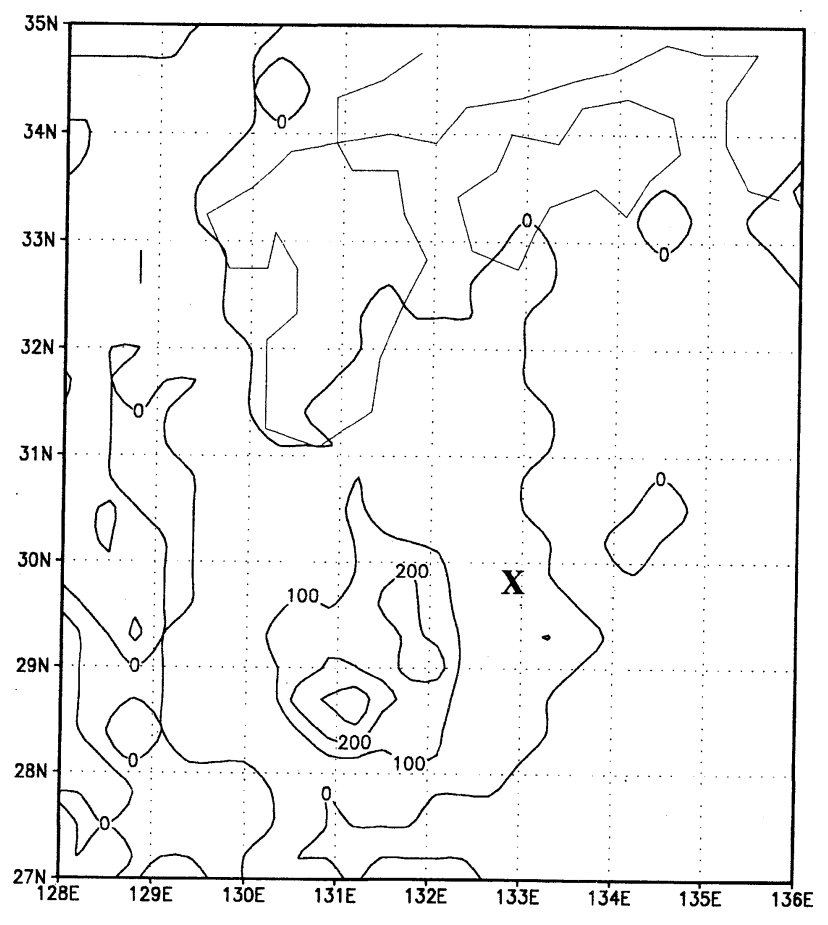

Fig. 10. Same as Fig. 5, but for PI. however, had the same slow spin-up of precipitation as RT to the east of the typhoon center, where no precipitation observational data were incorporated into the physical initialization.

Comparing this figure with Fig. 4 indicates that PI alleviated some of the positional errors in precipitation forecasts for 00-04 UTC: PI predicted heavier precipitation than RT along $131^{\circ} \mathrm{E}$ by strengthening convective precipitation for 00-02 UTC and generating the large-scale precipitation band after that time. Precipitation forecasts in the observed rain-free areas, especially the convective precipitation around Areas C and D were suppressed by PI.

The above results suggest that the physical initialization method gave a positive impact on qualitative precipitation forecasts during the first several hours. The impact, however, became insignificant beyond 4 hours into the forecast.

It is also found that the spin-up of large-scale precipitation from PI was much weaker than that from $\mathrm{RT}$ in the convective unstable region. This is because the initial nearly- saturated state, such as Area F, was alleviated by the humidity adjustment

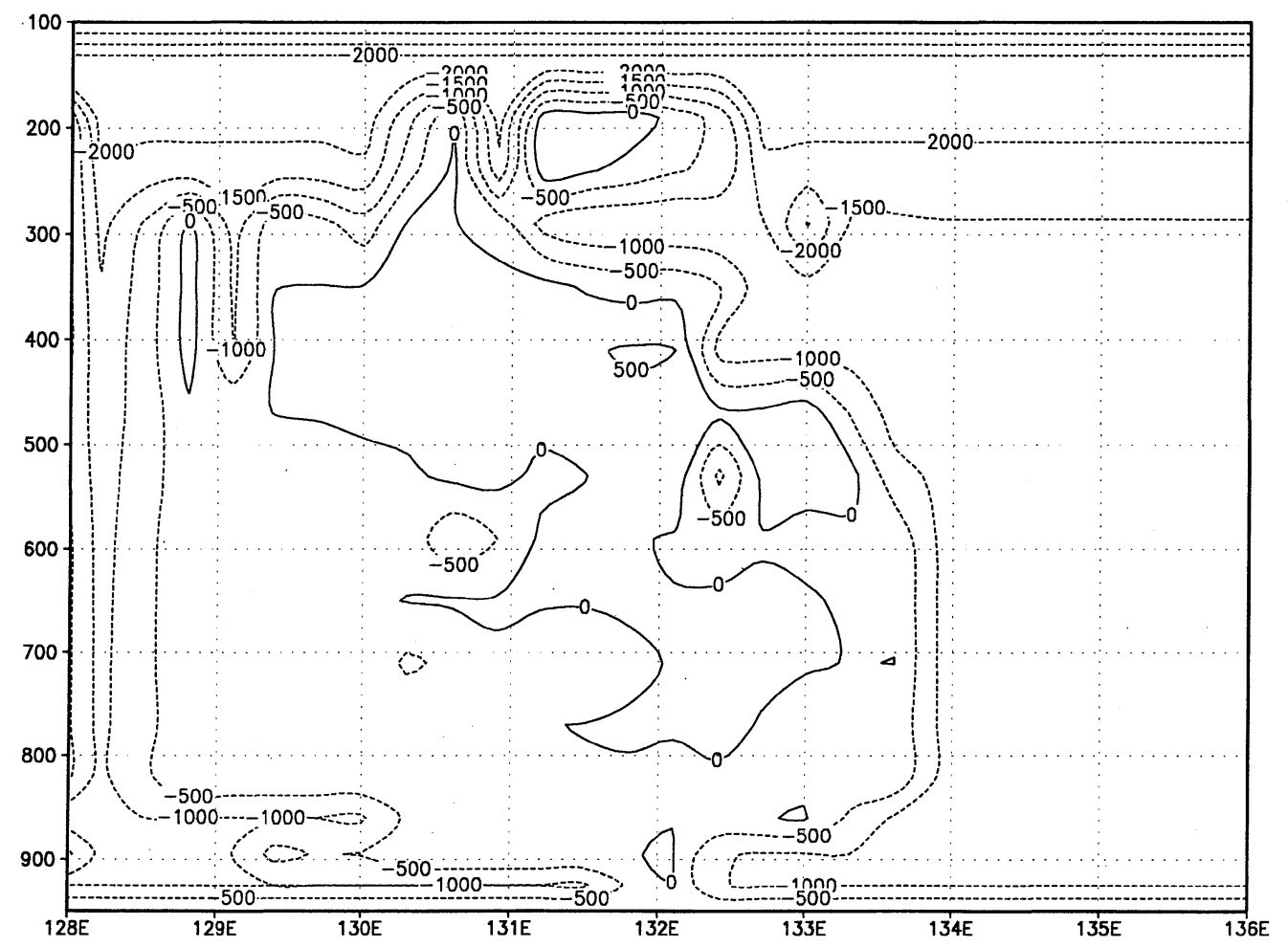

Fig. 11. Same as Fig. 6, but for PI. 


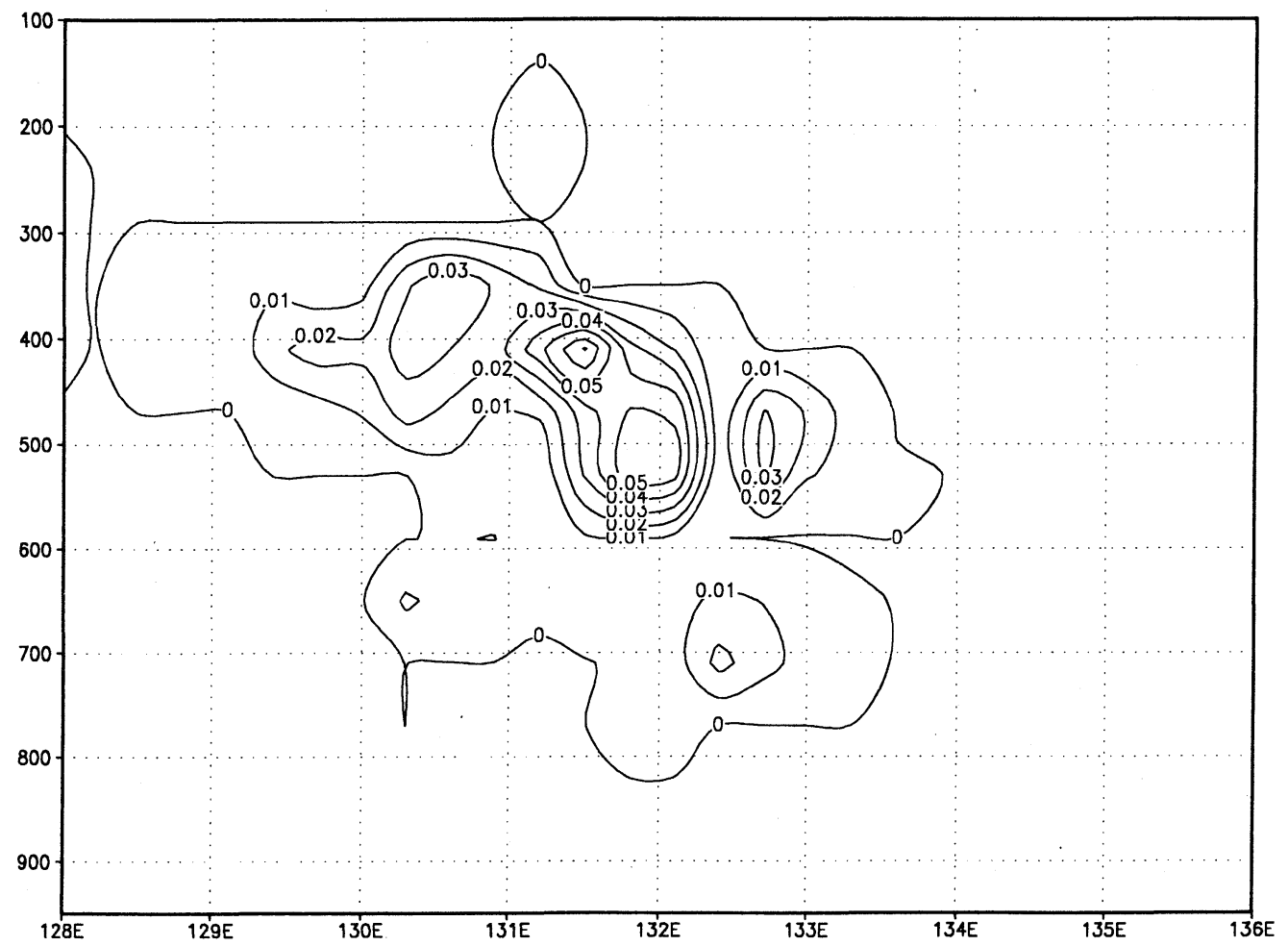

Fig. 12. A vertical cross section of the first guess of the cloud-base mass flux $\left(\mathrm{kg} \mathrm{m}^{2} \mathrm{~s}^{-1}\right)$ calculated from $\left(\frac{\partial A z t}{\partial t}\right)_{L S}$ at the initial time of PI.

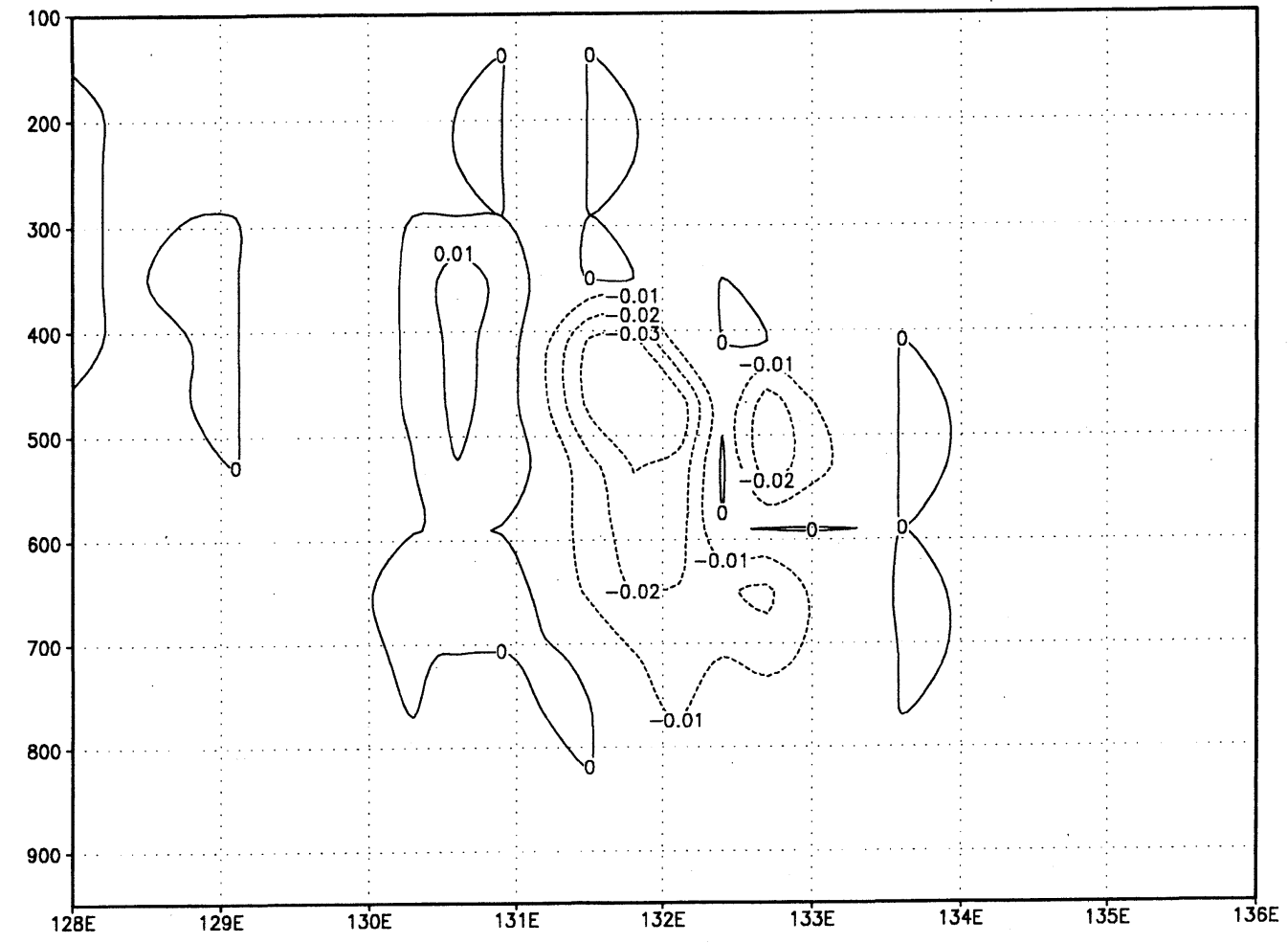

Fig. 13. A vertical cross section of adjustment of the cloud-base mass flux $\left(\mathrm{kg} \mathrm{m}^{2} \mathrm{~s}^{-1}\right)$. 


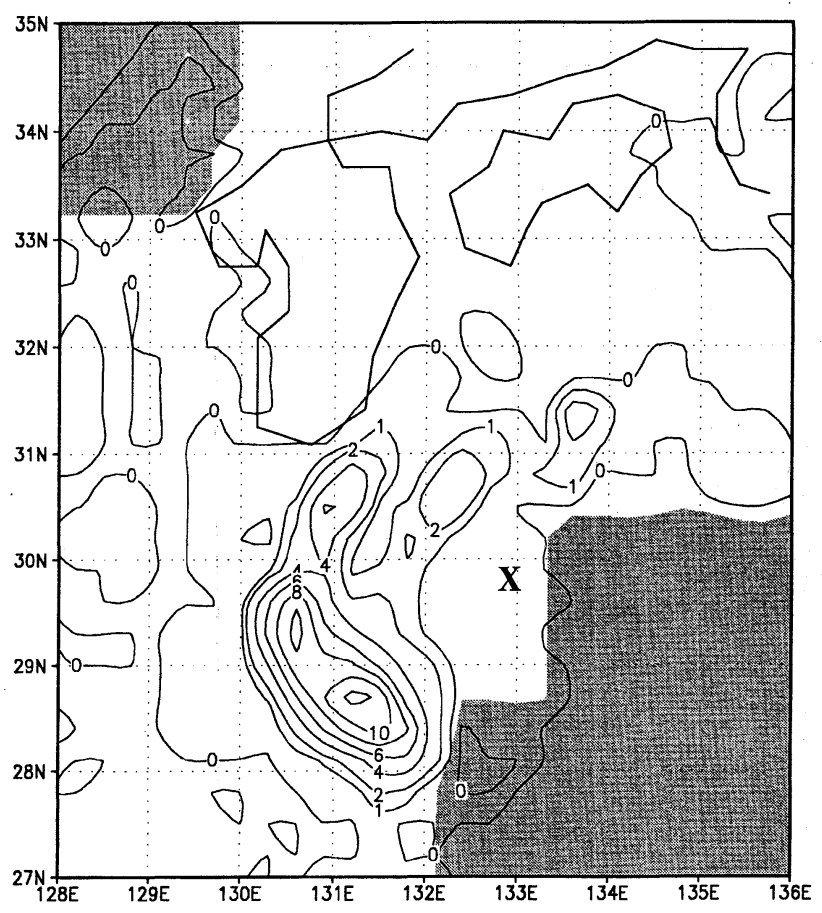

Fig. 14. The convective precipitation calculated from the initialized cloud base mass flux for PI. Contours are at $0,1,2$, $4,6,8,10,12,16,20 \mathrm{~mm} \mathrm{~h}^{-1}$. Shaded areas are out of the observation ranges of the hourly precipitation analysis. $X$ is the center of typhoon Walt.

to remove the extreme convective instability.

\subsection{The roles of the individual initialization proce- dures}

Figure 16 presents hourly precipitation forecasts for 00-04 UTC from experiment IM. Similar to PI, heavy precipitation was predicted by IM in Area A in 00-01 UTC. The heavy precipitation area (hereafter referred to as Area L), however, included Areas $\mathrm{C}$ and F. After 01 UTC, the precipitation forecasts from IM were also close to those from PI in precipitation distribution within $130^{\circ}-132^{\circ} \mathrm{E}$. The main difference is that IM had larger positional error of precipitation forecasts than PI, by generating stronger convective precipitation in Area D for 00-04 UTC, and by weakening precipitation around Area B.

The above results indicate that elimination of the extreme moist-convective instability alleviated the positional error of precipitation forecasts around Areas $\mathrm{C}$ and D. It was also found that the adjustment of the $\mathrm{RH}$ in the initial stable regions reduced the positional error of precipitation forecasts in Area B.

Figure 17 shows hourly precipitation forecasts for 00-04 UTC from experiment TH. The model precipitation for 00-01 UTC was very weak even in Areas $\mathrm{C}$ and D. The spin-up of the model convective precipitation occurred after 01 UTC. After this time, precipitation forecasts from $\mathrm{TH}$ was similar to those from RT : The model heavy-rain band by $\mathrm{TH}$ in the western sector was confined in $131^{\circ}-132^{\circ} \mathrm{E}$, just as RT. TH also had a convective precipitation band (hereafter referred to as Area M) in Area D for 0104 UTC, though the rain intensity was weaker than RT. TH, however, had more extensive precipitation areas than RT around Area B.

The above results of the forecast experiments confirm that the adjustment of the initial cloud-base mass flux was essential for eliminating the spin-up error of precipitation forecast in Area A for the first one hour. The adjustment also contributed to reduce the positional error of precipitation by strengthening the convective precipitation around A for the first few hours. It was also found that the model precipitation area in Area D was reduced by the adjustment of the initial cloud-base mass flux. We infer that, in experiment PI, the strengthened precipitation in $130^{\circ}-132^{\circ} \mathrm{E}$ suppressed the precipitation in this region.

\section{Summary and discussion}

In this study, we developed a physical initialization method for EPAS, a simplified ArakawaSchubert scheme. The technique consists of:

(1) Adjustment of the initial thermodynamic variables in such a way that the model precipitation areas come into correspondence with the observed precipitation areas at the initial time.

(2) Adjustment of the initial cloud-base mass flux in such a way that the model precipitation rates from the adjusted $\mathrm{Mb}$ are equal to the observed precipitation rates.

In order to examine the impacts of the physical initialization method, forecast experiments for a case study of Typhoon WALT (T9407) were performed.

A JSM without the physical initialization had a spin-up error in the precipitation forecast for the first hour and a positional error in precipitation forecasts .

The results of the experiments indicate that the physical initialization method of this study eliminated the spin-up error in the moist-convectively unstable region. The adjustment of the initial cloud base mass flux was essential for this improvement.

It was also found that the physical initialization reduced the positional error of precipitation forecasts for the first several hours. The adjustment of the initial thermodynamic variables reduced the positional error in the following ways:

(1) Removal of extreme moist-convective instability suppressed the model convective precipitation in the observed rain-free areas. 
(a) QPF (PI) for $00-01 \mathrm{z}(\mathrm{mm} / \mathrm{hr})$

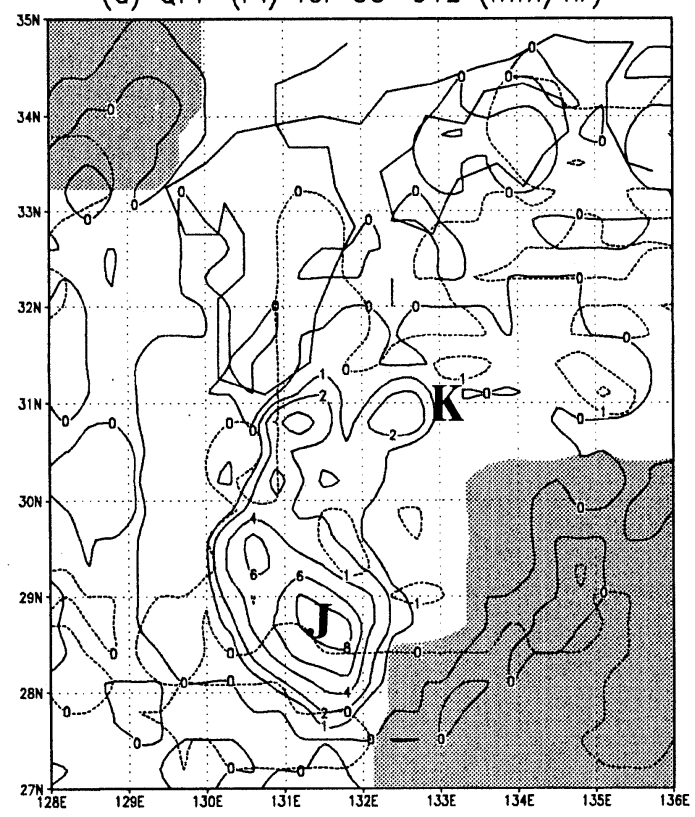

Gros: COMGES

(c) QPF (PI) for 02-03z (mm/hr)

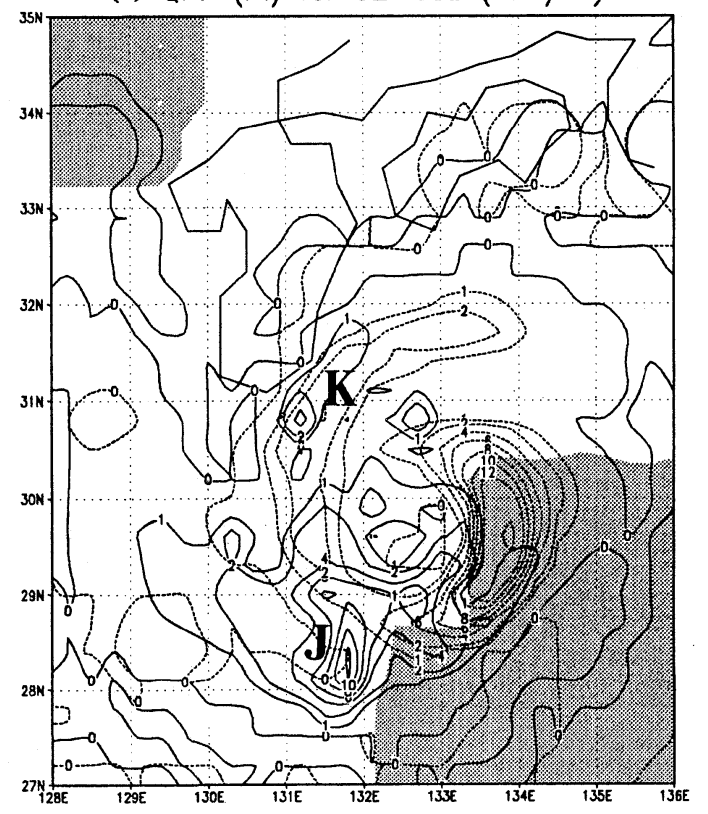

(b) QPF (PI) for 01-02z (mm/hr)

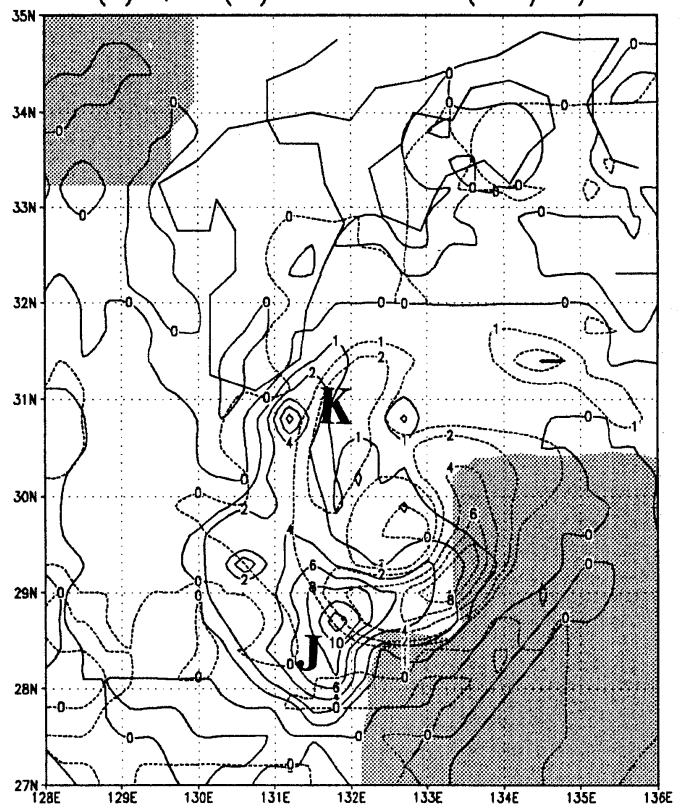

Gros: couMGes

(d) QPF (PI) for 03-04z (mm/hr)

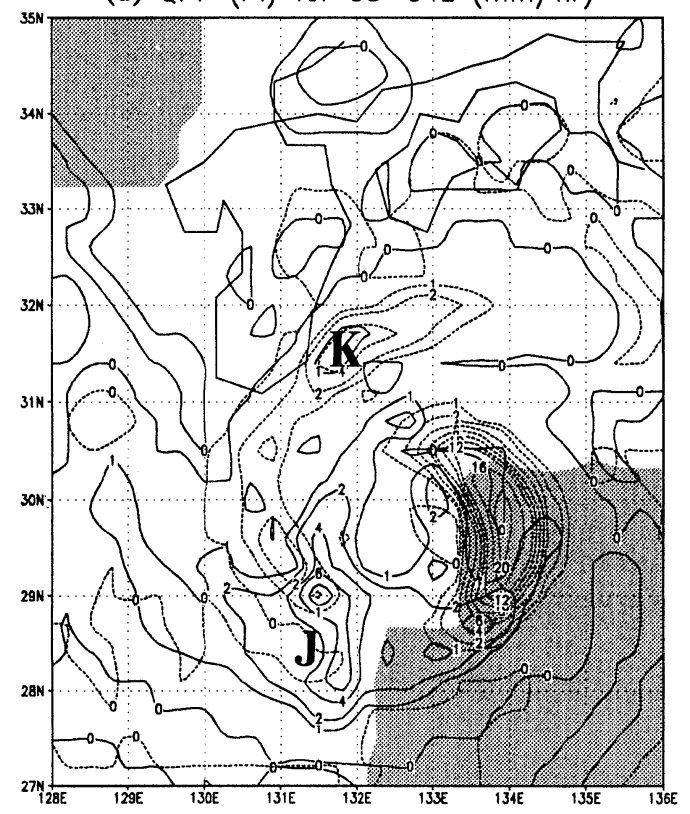

Fig. 15. Same as Fig. 8, but for PI. J and $\mathrm{K}$ represent model precipitation areas along $131^{\circ} \mathrm{E}$ and in the northern sector of the typhoon, respectively. 
(a) QPF (IM) for 00-01z (mm/hr)

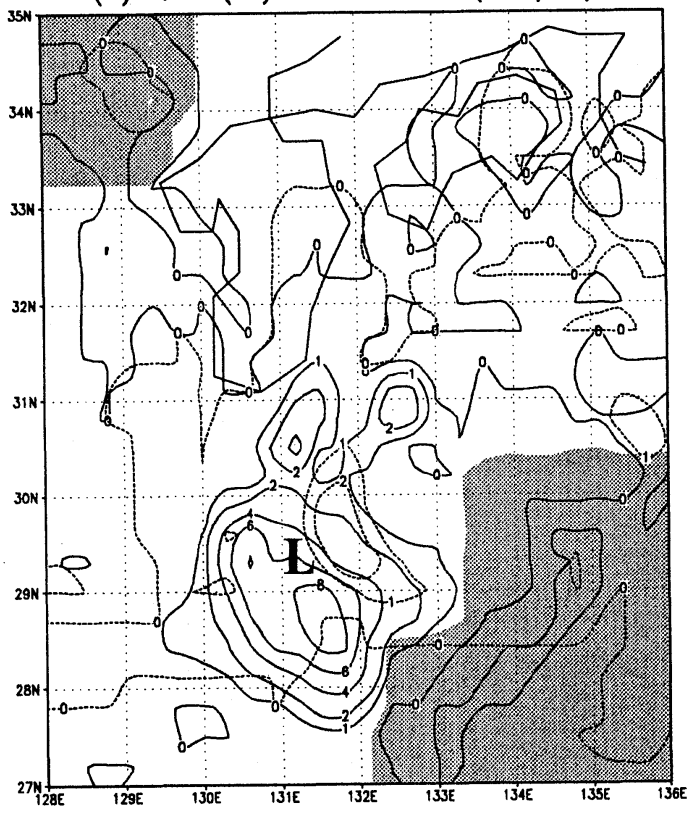

Gros: caunces

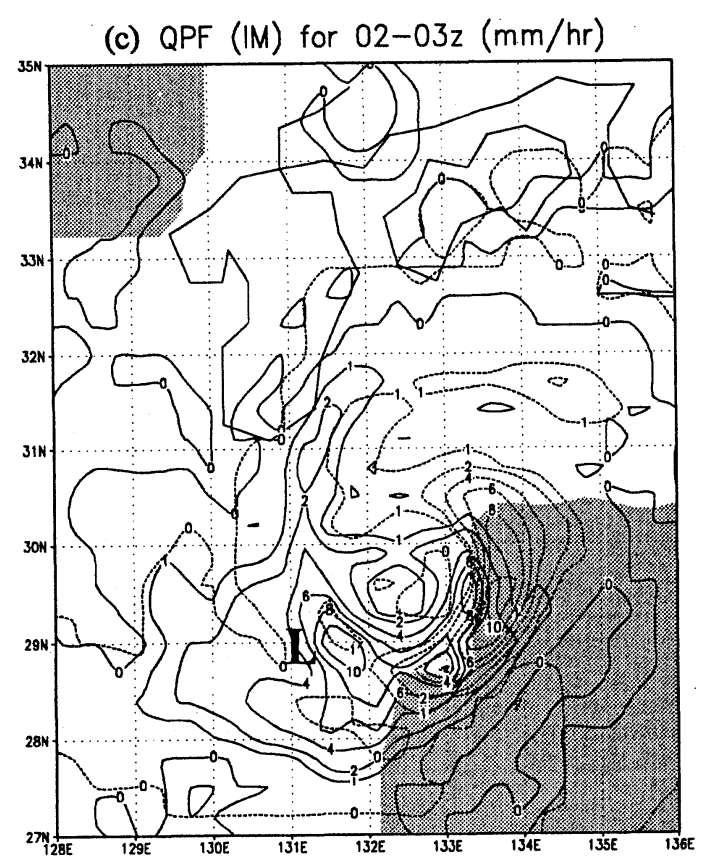

(b) QPF (IM) for 01-02z (mm/hr)

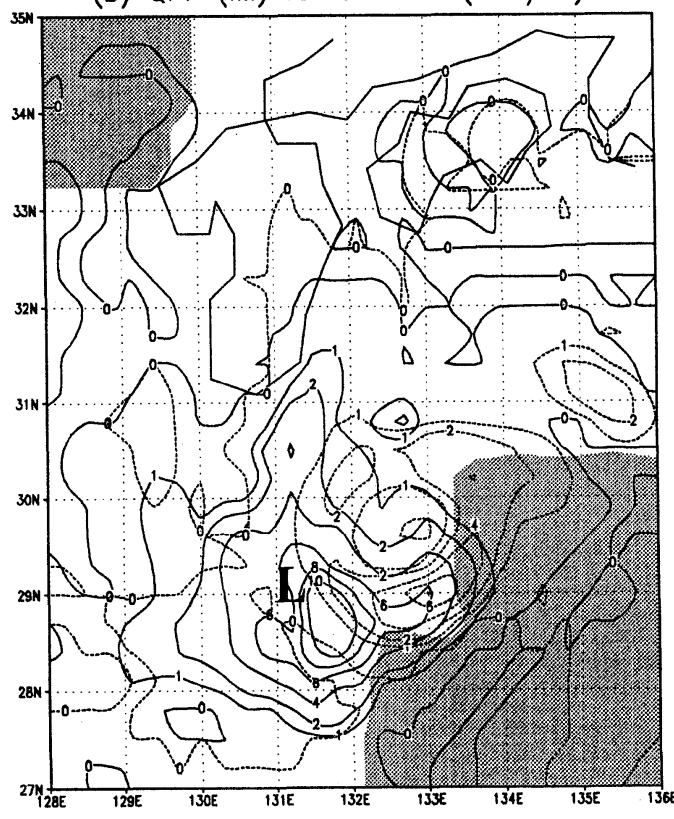

GROS: CaMMGes

(d) QPF (IM) for 03-04z (mm/hr)

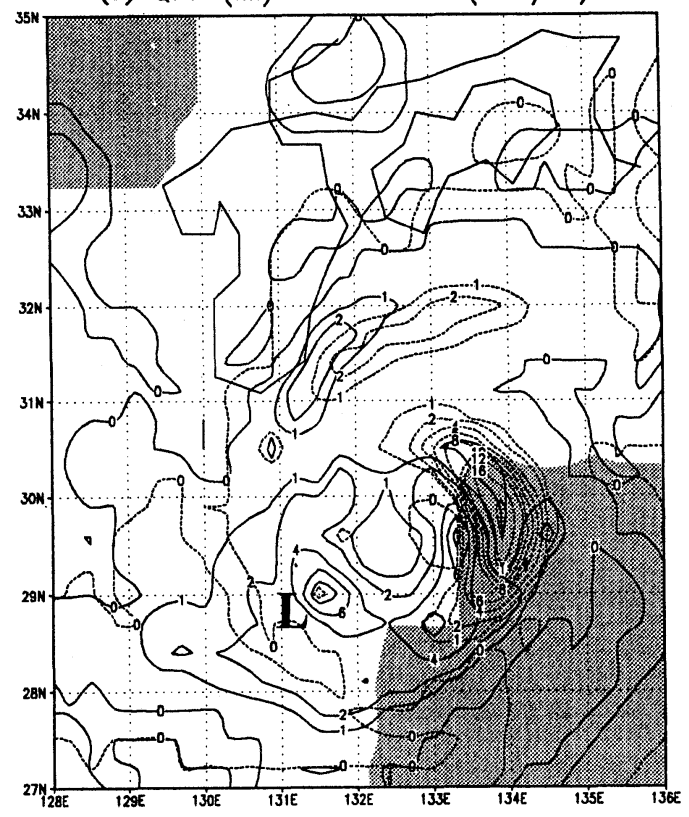

Fig. 16. Same as Fig. 8, but for IM. L represents a heavy-precipitation area to the west of the typhoon. 
(a) QPF (TH) for $00-01 \mathrm{z}(\mathrm{mm} / \mathrm{hr})$

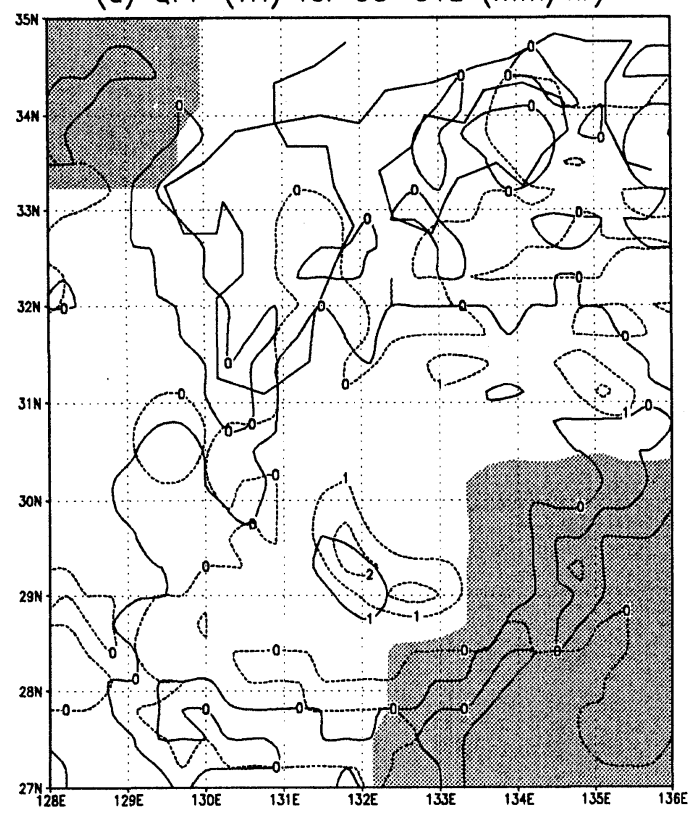

Gros: camaes

(c) QPF (TH) for $02-03 z(\mathrm{~mm} / \mathrm{hr})$

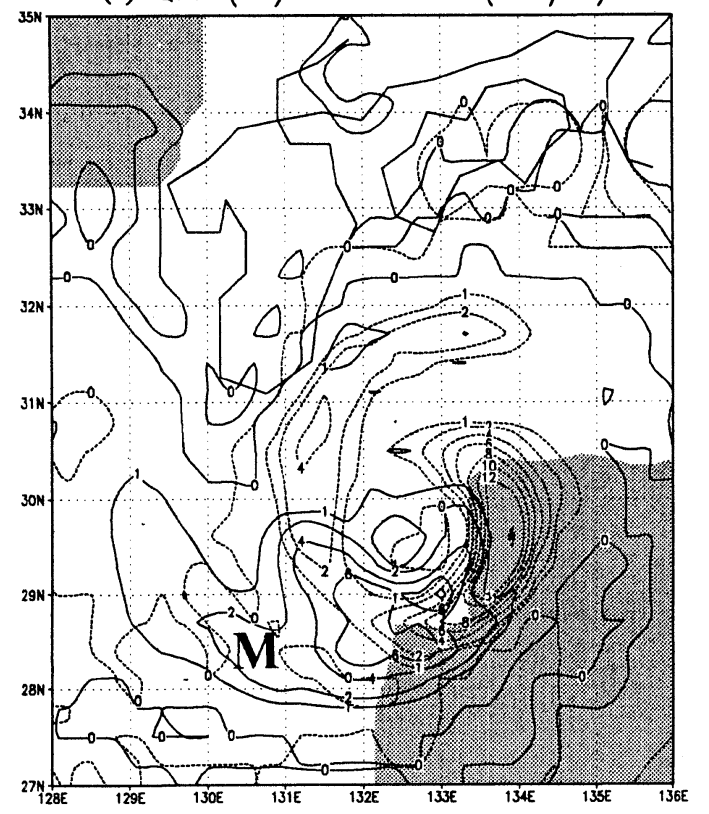

(b) QPF (TH) for $01-02 z(\mathrm{~mm} / \mathrm{hr})$

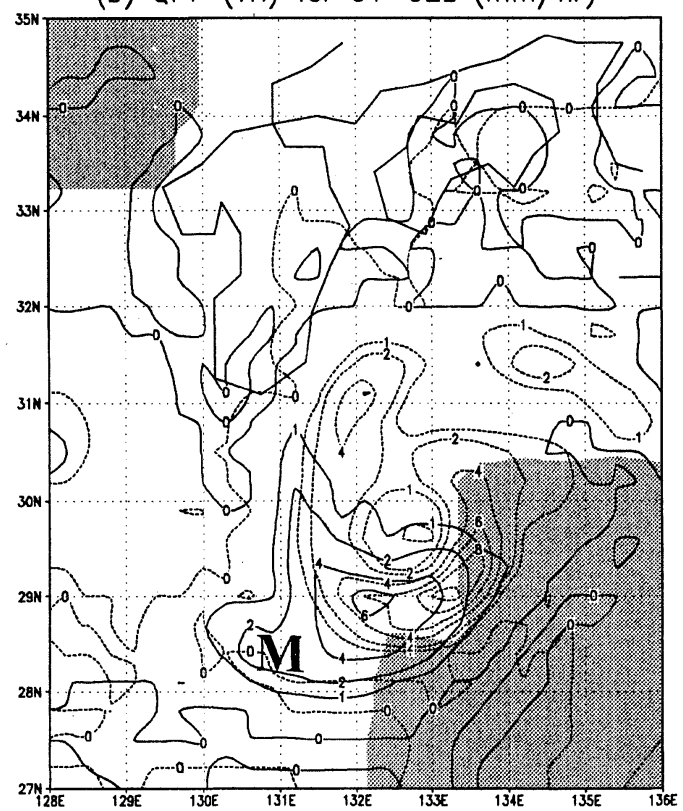

Gros: COMGES

(d) QPF (TH) for $03-04 z(\mathrm{~mm} / \mathrm{hr})$

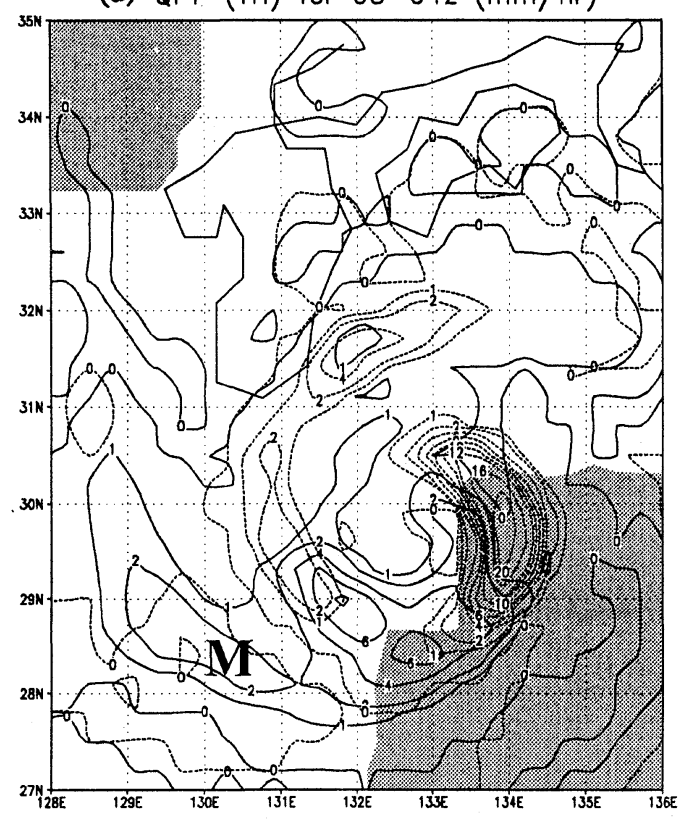

Fig. 17. Same as Fig.8, but for TH. M represents a convective precipitation band in the western sector of the typhoon. 
(2) Raising $\mathrm{RH}$ within convective stable regions contributed to generate the model large-scale precipitation in the observed rain areas.

The adjustment of the initial cloud-base mass flux also contributed to reduce the positional error by strengthening the model convective precipitation around the observed heavy-rain area.

The above results indicate that the extreme convective instability in RT was harmful to the precipitation forecasts of JSM using EPAS. Since the convective instability is sensitive to the thermodynamic variables in the lower boundary layer, we think that these extremely unstable regions were caused mainly by the objective analysis for this layer. This is because, as described in Section 2, the first guess for the objective analysis (the 12-hour forecast of JSM using EPAS) was nearly neutral or stable for EPAS. Accordingly, careful objective analysis procedures are required, especially near ground level, in order not to generate extreme convective instability.

Though the results of the experiments are encouraging, there remains some problems to be solved.

First, the impact of the physical initialization method lasted only for a few hours. This is contrary to the recent studies of Peng and Chang (1996) (Hereafter referred to as PC.) and Shi et al. (1996) (Hereafter referred to as $\mathrm{SH}$.) on the impacts of assimilating precipitation data on tropical cyclones. One possible reason is the difference in the strength of the initial vortices of the cyclones. As Fig. 2 shows, the bogussing procedures of the objective analysis generated a strong typhoon vortex before the physical initialization. On the contrary, both $\mathrm{PC}$ and $\mathrm{SH}$ seemed to give to their control forecasts cyclone vortices weaker than in reality, as $\mathrm{SH}$ discussed. SH also pointed out that the impact of assimilating precipitation was limited when the initial cyclone vortex was intensified by assimilating in-situ observation data. From the above discussion, it is inferred that the impacts for case studies of PC and $\mathrm{SH}$ were long-lasted because assimilating precipitation enhanced the unrealistically weak cyclone vortices, and that the impact of this study was short-lived because the vortex of the initial field was already realistically strong. In order to confirm this inference, it is required to study interactions between evolution of the typhoon vortex and precipitation. Another possible reason for the short duration is that the precipitation observation for this study was confined to the west of the typhoon, while $\mathrm{PC}$ and $\mathrm{SH}$ utilized precipitation data covering the whole of their cyclones. This may suggest that precipitation data over the entire domain of typhoons are needed for controlling the typhoon vortices. Accordingly, we are planning to examine the impacts of data coverage on the forecasts using remotely-sensed precipitation data sets over wide regions.
Next, large-scale condensation is expected to coexist with the convective precipitation in the vicinity of the typhoon center, since the atmosphere is considered to be nearly convectively-neutral there. Although it was found that the spin-up of large-scale precipitation from PI became weaker than RT in the convective unstable region around the typhoon. This is because the nearly-saturated areas in the first guess were alleviated by the adjustment of the initial thermodynamic variables. If we have additional information on regions with convective-neutrality, it is easy to construct the physical initialization method satisfying the coexistence of large scale condensation with convective precipitation. Hence, the main difficulty in solving this problem lies in determining the nearly convectively-neutral regions. We think that the information on the type of precipitation (i.e. stratiform or convective) can be used as this index.

Further, there remains the uncertainty in determining the cloud-top levels in the initialization method. This is mainly because of the lack of information on vertical precipitation profiles. In order to alleviate this difficulty, it is necessary to research the retrieval of the vertical precipitation profiles from remote sensing data.

In spite of the above problems, the results indicate that the physical initialization described in this study is useful to improve precipitation forecasts. Before generalizing these results, however, more experiments must be performed for a variety of meteorological cases.

\section{Acknowledgements}

The Numerical Prediction Division, JMA provided the basic version of the numerical prediction models and the objective analysis data. The hourly precipitation data were provided by the Forecast Division, JMA. Satellite cloud images were provided by the Meteorological Satellite Center. The authors express their thanks to Mr. Kazuo Kurihara and Dr. Mitsuru Ueno and Mr. Tomoaki Ose for their fruitful discussions, to Dr. Noel E. Davidson for carefully reading the manuscript, and to two anonymous reviewers for valuable comments.

\section{References}

Aonashi, K., 1993: An initialization method to incorporate precipitation data into a mesoscale numerical weather prediction model. J. Meteor. Soc. Japan, 71, 393-406.

Aonashi, K. and A. Shibata, 1996: The impact of assimilating SSM/I precipitable and rain flag data on humidity analysis and short-term precipitation forecasts. J. Meteor. Soc. Japan, 74, 77-99.

Arakawa, A. and W.H. Schubert, 1974: Interaction of a cumulus cloud ensemble with the large-scale environment, Part I. J. Atmos. Sci., 31, 674-701. 
Donner, L.J., 1988: An initialization for cumulus convection in numerical weather prediction models. Mon. Wea. Rev., 116, 377-385.

Gadd, AJ. and J.F. Keers, 1970: Surface exchange of sensible and latent heat in a 10-level model atmosphere. Quart. J. Roy. Meteor. Soc., 96, 297-308.

Kasahara, A., J. Tsutsui, and H. Hirakuchi, 1996: Inversion methods of three cumulus parameterizations for diabatic initialization of a Tropical cyclone model. Mon. Wea. Rev., 124, 2304-2321.

Kuma,K., 1993: Impact of EPAS on Typhoon forecasts by a global NWP model. Proceedings of the 63rd Conference of Japan Meteorological Society, 208. (in Japanese).

Kashiwagi, K., 1990: Summary of the operational objective analysis systems. "Meteorological Data and Objective Analysis" Technical Report of JMA/NPD Vol.36, Japan Meteor. Agency, 60-65. (in Japanese).

Krishnamurti, T.N., K. Ingles, S. Cooke, T. Kitade and R. Pasch, 1984: Details of low-latitude, mediumrange numerical weather prediction using a global spectral model. Part 2: Effects of orography and physical initialization. J. Meteor. Soc. Japan, 62, 613-648.

Machenhauer, B., 1977: On the dynamics of gravity oscillations in a shallow water model, with application to normal model initialization. Beitr. Phys. Atmos., 50, 253-271.

NPD, 1989: "Meteorological Data and Objective Analysis" Technical Report of JMA/NPD Vol.36, Japan Meteor. Agency. (in Japanese).
Peng, M.S. and S.W. Chang, 1996 : Impacts of SSM/I Retrieved Rainfall Rates on Numerical Prediction of a Tropical Cyclone. Mon. Wea. Rev., 124, 11811198.

Randall, D.A. and D.M. Pan, 1993: Implementation of The Arakawa Shubert Cumulus Parameterization with a Prognostic Closure. Meteor. Monographs, 46, 137-144.

Segami, A., K. Kurihara, H. Nakamura, M. Ueno, I. Takano and Y. Tatsumi, 1989: Operational mesoscale weather prediction with Japan Spectral Model. J. Meteor. Soc. Japan, 67, 907-924.

Shi, J.J., S. Chang and S. Raman, 1996: Impacts of Assimilations of Dropwindsonde Data and SSM/I Rain Rates on Numerical Prediction of Hurricane Florence(1988). Mon. Wea. Rev., 124, 1435-1448.

Takàse, K., Y. Takemura, K. Aonashi, N. Kitabatake, Y. Makihara and Y. Nyomura, 1988: Operational precipitation observation system in Japan Meteorological Agency. "Tropical Rainfall Measurements" J.S.Theon and N.Fugono, editors, A.DEEPACK publishing, 407-413.

Turpeinen, O.M., L. Garand, R. Benoit and M. Roch, 1990: Diabatic initialization of the Canadian regional finite-element (RFE) model using satellite data Part I: Methodology and Application to a winter storm. Mon. Wea. Rev., 118, 1381-1395.

Ueno, M., 1989: "Operational Bogussing and Numerical Prediction in JMA" JMA/NPD Technical Report No. 28, Japan Meteor. Agency. 


\title{
Economical Prognostic Arakawa-Schubert スキムについての物理的初期值化手法
}

\author{
青梨和正 \\ (気象研究所) \\ 隈 健一・松下康広
}

(気象庁数值予報課)

\begin{abstract}
降水の観測データを数值予報モデルへ導入するため、Arakawa-Schubert 型スキムの1つである、Economical Prognostic Arakawa-Schubert (EPAS)スキムについての物理的初期值化手法を開発した. 本研究 の物理的初期値化手法は、変分法を用いて、降水域と降水強度についての強い拘束条件のもとで初期值化 されたモデル予報変数と第 1 推定值との差を最小にするものである。E P A S の降水に関する仮定を適用 すると、この物理的初期値化手法は以下の $2 つ の$ 部分に分けられる：(1)初期の熱力学場の補正によってモ デル降水域を初期の観測降水域と同じにする。(2)初期のCloud Base Mass Flux の補正によってモデル降 水強度を初期の観測降水強度と等しくする。

この物理的初期値化手法の効果を調べるために、台風 9407 号の周辺のレーダーアメダス解析雨量を導 入した予報実験( ‘ 94 年 7 月 23 日 $00 \mathrm{Z}$ 初期) を行なった。この予報実験の結果は、本研究の物理的初期值化 手法は、最初の 1 時間に見られた降水予報の立ち上がり誤差を解消したこと、また数時間にわたって降水 予報の位置ずれ誤差を減少させたことを示す。これらの結果以下のことを示唆している：(1)初期の Cloud Base Mass Fluxの補正が降水予報の立ち上がり誤差の解消に不可欠である。(2)初期の Cloud Base Mass Fluxの補正は観測の強雨域付近でモデルの対流性降水を強めることで降水予報の位置ずれの減少に寄与し ている。(3) 初期の熱力学場の補正は観測非降水域内の非常に対流不安定な部分を除去することで降水予報 の位置ずれの改善に寄与している。
\end{abstract}

